\title{
Participación colectiva de víctimas ante la Jurisdicción Especial para la Paz (JEP)*
}

\section{Collective Participation of Victims before the Special Jurisdiction for Peace (JEP)}

\author{
Juliette Vargas Trujillo ${ }^{\text {a }}$ \\ Centro de Derecho Penal y Procesal Penal Latinoamericano \\ (CEDPAL), Alemania \\ juliette.vargas@instituto-capaz.org \\ ORCID: https://orcid.org/0000-0002-9962-167X
}

DOI: https://doi.org/10.11144/Javeriana.vj69.pcvj

Fecha de recepción: 05 Noviembre 2019

Fecha de aprobación: 03 Diciembre 2019

Fecha de publicación: 30 Junio 2020

\section{Resumen:}

Uno de los grandes desafíos que debe afrontar la Jurisdicción Especial para la Paz (JEP) para asegurar una participación real y significativa de las víctimas es implementar mecanismos idóneos de participación colectiva. Si bien la JEP ya ha establecido la participación colectiva a través de representante legal común como mecanismo para asegurar la participación amplia de víctimas, aún no se han concretado los parámetros que definen cómo debe operar. Con base en las dificultades y críticas que han surgido de algunas experiencias en el contexto de Justicia y Paz en Colombia y de escenarios internacionales como la Corte Penal Internacional, el objetivo de este artículo es visibilizar algunos aspectos y lecciones aprendidas notables que se pueden tener en cuenta para formular e implementar medidas acertadas al respecto. Este estudio plantea que la participación colectiva a través de representante legal puede fácilmente convertirse en una participación meramente simbólica a partir de factores como la homogenización de las víctimas, la ausencia de comunicación entre éstas y sus representantes, y la no concesión de un mínimo de incidencia en la escogencia de su representante y en los criterios de agrupación.

Palabras clave: víctimas, justicia transicional, participación colectiva, interviniente especial, Jurisdicción Especial para la Paz, Colombia.

\begin{abstract}
:
One of the great challenges the Special Jurisdiction for Peace (JEP) should face, in order to ensure real and meaningful participation of victims, is to implement suitable mechanisms for collective participation. Although collective participation through a common legal representative has already been established as a mechanism to ensure broad participation of victims before the JEP, the parameters defining how it should operate have not yet been defined. Based on the difficulties and criticism that have arisen from some experiences in the context of "Justicia y Paz" in Colombia, and of international scenarios such as the International Criminal Court, the objective of this article is to highlight some notable aspects and lessons learned that could be taken into account in order to formulate and implement appropriate measures in this regard. This study states that collective participation through legal representatives can easily become a merely symbolic participation based on factors such as the homogenization of victims, the absence of communication between victims and their representatives, and the failure to grant a minimum of agency the selection of their representative and in the grouping criteria.
\end{abstract}

Keywords: victims, transitional justice, collective participation, special intervener, Special Jurisdiction for Peace, Colombia.

\section{Introducción}

En el contexto actual de la Justicia Transicional en Colombia, la JEP, como componente judicial del Sistema Integral de Verdad, Justicia Reparación y No Repetición (SIVJRNR), tiene prevista la participación de víctimas en los procedimientos con motivo de la investigación y juzgamiento de los crímenes de guerra y de lesa humanidad, entre otros crímenes, cometidos en el marco del conflicto armado colombiano. Dada la envergadura de los crímenes de competencia de la JEP y las complejas dimensiones del conflicto armado de más de 50 años de duración, el número de afectaciones y de víctimas es extraordinariamente alto ${ }^{[1]}$. Aunado

Notas de autor

a Autora de correspondencia. Correo electrónico: juliette.vargas@instituto-capaz.org 
a ello, los siete casos priorizados hasta la fecha por la $\mathrm{JEP}^{[2]}$ abordan patrones de macrocriminalidad ${ }^{[3]} \mathrm{y}$ algunos de estos incluso tienen connotación nacional ${ }^{[4]}$, por lo que se puede prever una participación masiva de víctimas.

La experiencia en escenarios de justicia penal internacional ha demostrado que la participación de víctimas es un aspecto complejo, especialmente cuando se trata de casos que implican macrovictimizaciones ${ }^{[5]}$. Dada la masividad de víctimas que eventualmente pueden participar en los procedimientos penales, y con el fin de que tal participación no desborde las capacidades de las Cortes, se establecen diferentes mecanismos de participación colectiva a través de representantes legales comunes y en algunos casos se restringen las modalidades de participación ${ }^{[6]}$. Sin embargo, cabe preguntarse hasta qué punto esta participación colectiva puede convertirse en algo meramente simbólico, y si realmente puede interpretarse como una participación significativa de las víctimas ${ }^{[7]}$.

Precisamente, con motivo de la primera Sentencia Interpretativa (SENIT) de la Sección de Apelaciones del Tribunal para la Paz de la JEP (TP-SA) de 3 de abril de 2019, que ordena a la Secretaría Ejecutiva de esta jurisdicción "diseñar y operar un sistema de coordinación con el objetivo de lograr una acción coordinada de participación colectiva de víctimas" ${ }^{[8]}$, estas inquietudes cobran de nuevo vigencia en Colombia. Actualmente, ya hay algunos colectivos étnicos en todo el país que se encuentran representados a través del Sistema Autónomo de Asesoría y Defensa de la JEP (SAAD) ${ }^{[9]}$. No obstante, aún no se ha establecido un protocolo o unos criterios formales que determinen, entre otras cuestiones, cómo se implementará la participación colectiva en casos de víctimas que no corresponden a colectivos étnicos y, por ende, que no están agrupadas en razón a esta pertenencia. Por ello, vale la pena analizar algunas experiencias de participación colectiva en otros escenarios análogos para identificar lecciones aprendidas y aspectos esenciales que se deben tener en cuenta para lograr esta tarea, especialmente para que no se desnaturalice el sentido de la participación de las víctimas desde el paradigma de centralidad de las mismas que se ha propuesto como eje del SIVJRNR ${ }^{[10]}$.

Es evidente que la JEP se ha planteado como mecanismo judicial con particularidades tales que no permite comparaciones simplistas con modelos de participación de víctimas aplicados en otros escenarios de justicia penal internacional y de justicia transicional. Sin embargo, la experiencia de los juicios de "Justicia y Paz" en Colombia figura como antecedente inmediato de la JEP, y permite identificar falencias y logros que hacen parte de los referentes necesarios para afrontar los retos actuales de la Justicia Transicional. Por otra parte, es interesante observar cómo ha operado la participación de víctimas en la Corte Penal Internacional (CPI) y ante las Salas Extraordinarias en las Cortes de Camboya (ECCC, por sus siglas en inglés), teniendo en cuenta que estos tribunales marcan un hito en la historia de la Justicia Penal Internacional, entre otras razones, por dar a las víctimas un rol inédito hasta entonces ${ }^{[11]}$. En consecuencia, estos tres escenarios serán tenidos en cuenta como referente para el análisis que se propone.

Cabe aclarar que una participación efectiva y significativa de las víctimas en los procedimientos penales no depende únicamente de la coordinación colectiva de la participación o de la representación legal. Es evidente que otros factores como el acompañamiento psicosocial, las medidas de protección y seguridad, y las medidas restaurativas y de acompañamiento fuera de los tribunales son también fundamentales; sin embargo, en este artículo solo se aborda el tema de la participación colectiva desde el punto de vista de la representación y asesoría legal, teniendo en cuenta las limitaciones de formato. En ese sentido, en este estudio se plantea básicamente que la participación colectiva a través de un representante legal puede fácilmente convertirse en una participación meramente simbólica a partir de factores como la homogenización de las víctimas, la ausencia de comunicación entre éstas y sus representantes, y la no concesión de un mínimo de incidencia a éstas en la escogencia de su representante y en los criterios de agrupación.

Metodológicamente el artículo se vale de la normatividad, decisiones judiciales, libros y artículos de análisis, así como de informes de organizaciones de la sociedad civil para hacer referencia a las experiencias de la CPI, 
las ECCC y de Justicia y Paz. Por otra parte, dado que se trata de un tema incipiente y hasta ahora en desarrollo en el contexto de la JEP, las fuentes de información han sido principalmente respuestas a derechos de petición dirigidos a la JEP, la observación de algunas audiencias de carácter público de la JEP, así como el análisis del marco normativo y desarrollos jurisprudenciales relacionados con el tema provenientes tanto de la Corte Constitucional como de la JEP misma.

En la primera parte del artículo se hará una distinción conceptual entre las ventajas y desventajas generales de la participación colectiva de víctimas en procedimientos penales con el fin de entender las posibilidades que ésta brinda en términos de incidencia y satisfacción de intereses de las víctimas. En la segunda parte se explicará el marco jurídico de la JEP que sirve de base a la participación de víctimas, teniendo en cuenta los desarrollos jurisprudenciales e identificando los avances que se han hecho hasta el momento en este terreno. En la tercera parte se expondrán los desafíos, lecciones aprendidas, logros y falencias más notables que se pueden extraer de las experiencias de la CPI, de las ECCC y de Justicia y Paz respecto a los aspectos problemáticos identificados de la participación colectiva de víctimas. Finalmente, con base en la referencia a las experiencias y aspectos problemáticos de las experiencias analizadas en la sección anterior se identificarán aspectos que pueden llegar a ser problemáticos para la JEP, dada la ausencia de regulación o falta de claridad sobre cómo implementar lo establecido. Así, preguntas referentes a la forma de establecer o delimitar el número de víctimas por representante legal común, los criterios de agrupación de las víctimas, o criterios para escoger a los representantes legales se analizarán como aspectos problemáticos y se abordarán varias propuestas para el diseño e implementación de mecanismos de participación colectiva en el caso específico de la JEP, dada su naturaleza y el contexto colombiano.

\section{Caracterización de la participación colectiva de víctimas en procedimientos penales}

La participación de las víctimas en procedimientos penales tiene diferentes modalidades en escenarios de justicia penal internacional o justicia transicional. Con base en la tipología de Taylor, las víctimas tienen formas de participación directa como proveedoras de información cuando actúan como testigos ante un tribunal, o cuando tienen posibilidad de expresión incidental a través de declaraciones de impacto en la tradición anglosajona con el fin de determinar la sentencia de la persona condenada ${ }^{[12]}$.

No obstante, gran parte de las prerrogativas de las víctimas que participan en procedimientos penales se lleva a cabo por excelencia a través de representante legal, dada la complejidad de los aspectos técnico-jurídicos que conlleva el desarrollo del proceso penal. Esto quiere decir que la mayoría de derechos de participación de las víctimas en procedimientos penales se ejercen de manera indirecta, con el propósito de asegurar que una persona capacitada en aspectos jurídicos procesales y sustanciales asesore debidamente a la víctima y actúe en su nombre y representación para defender sus intereses. Parte de las garantías de acceso a la justicia de las víctimas es precisamente contar con representación legal para las actuaciones que así lo requieran ${ }^{[13]}$.

En escenarios en los que se juzgan casos de violaciones masivas de los derechos humanos o graves infracciones del derecho internacional humanitario, normalmente la participación de víctimas tiene lugar a través de representante legal común, debido a que las dimensiones de macrocriminalidad, por tratarse de crímenes internacionales, conlleva asimismo abordar macrovictimizaciones. ${ }^{[14]}$ En otras palabras, la gravedad y gran escala de los crímenes que se investigan se traduce en un número indeterminado o muy alto de víctimas. Por lo tanto, la única manera de hacer posible que un número elevado de víctimas pueda participar en los procedimientos sin colapsar a los tribunales es a través de mecanismos de participación colectiva por medio de representante legal común ${ }^{[15]}$. 


\section{Ventajas}

Este tipo de participación tiene algunas ventajas que vale la pena resaltar, teniendo en cuenta los desafíos que se presentan cuando hay un número alto de víctimas que desean participar en los procedimientos. En primer lugar, los mecanismos colectivos de participación permiten, como lo enuncia su nombre, una participación amplia de víctimas, que de otro modo quedaría restringida ante la imposibilidad de lidiar con un número alto de personas actuando cada una de manera individual a lo largo del proceso penal.

En segundo lugar, en términos muy operativos, la participación colectiva permite la sostenibilidad del sistema de representación gratuito proporcionado por la institucionalidad correspondiente para las víctimas que no cuentan con recursos para pagarlo. Es decir, ante las obvias limitaciones de presupuesto para el funcionamiento de un tribunal que debe garantizar el derecho de participación y de representación legal gratuita, la participación colectiva a través de un apoderado común es una alternativa que permite asegurar este derecho a un número elevado de víctimas ${ }^{[16]}$.

En tercer lugar, este tipo de participación posibilita a las víctimas que sus intereses sean representados sin necesidad de que su presencia física sea requerida en cada audiencia, trámite o diligencia. Es decir, sea porque su representante legal es quien atiende personalmente a las audiencias o sea porque algunos voceros de las víctimas toman parte directamente en las diligencias, la participación colectiva facilita la participación indirecta. En términos de seguridad y protección para las víctimas, así como en términos de costos y tiempo que implicaría una participación directa e individual, esta es una alternativa que permite, en teoría, que su participación no los ponga en riesgo o que sean excluidos por no tener los recursos para movilizarse y estar presentes en el tribunal correspondiente ${ }^{[17]}$.

La participación colectiva también puede eventualmente fomentar y fortalecer procesos de organización de víctimas cuando hay identidad de intereses y objetivos. A través de representante legal común, la participación colectiva es una alternativa para víctimas que, aun cuando quieren que alguien actúe a favor de sus intereses, no desean tener contacto directo con sus victimarios, y en ese sentido, este tipo de participación puede servir como mecanismo de protección para evitar traumas o revictimizaciones ${ }^{[18]}$.

\section{Desventajas}

En primer lugar, este tipo de participación pone en riesgo la individualidad de las víctimas cuando se homogenizan los intereses del grupo y no se tienen en cuenta las opiniones y preocupaciones particulares o disidentes. Esto puede ocurrir cuando dentro del grupo hay voces líderes que se tienen por voces legítimas, pero que no necesariamente representan los intereses de todo el colectivo. En ese sentido, la participación masiva en los procedimientos implica no solo que las víctimas deban participan a través de $\mathrm{su}(\mathrm{s})$ representante(s) legal(es), sino que son subsumidas dentro de una posición de grupo, aun cuando no compartan las mismas opiniones o intereses ${ }^{[19]}$.

En segundo lugar, la participación colectiva puede significar un distanciamiento de las verdaderas dinámicas y posibilidades del proceso si no hay una verdadera comunicación y procesos de consulta eficaces entre las víctimas como colectivo, y entre víctimas y el representante legal. En tercer lugar, esta misma falta de comunicación y consulta puede traer como consecuencia la desinformación de las víctimas y por ende la pérdida de confianza o del interés en el procedimiento penal. Sumado a ello, la falta de comunicación también puede llegar a reflejarse en la imposibilidad de que el representante entienda el contexto y particularidades de las víctimas a quienes representa. Esto significaría que este tipo de participación podría restringir o incluso suprimir la capacidad de incidencia de las víctimas ${ }^{[20]}$. 


\section{Marco Jurídico y caracterización de la participación de víctimas ante la JEP}

Es necesario aclarar que la JEP, como componente judicial del SIVJRNR, tiene rasgos definitorios particulares que necesariamente irradian los mecanismos de participación de víctimas. Por una parte, la JEP plantea un procedimiento de carácter adversarial para casos de no reconocimiento de verdad, que otorga a las víctimas la calidad de "intervinientes especiales" ${ }^{[21]}$. Por otra parte, en virtud del principio de "dialógico", se tiene un procedimiento de carácter deliberativo a modo de diálogo con participación de víctimas y comparecientes ante la JEP, que se aplicará en los casos de reconocimiento de verdad y que debe ser privilegiado sobre el principio adversarial cuando a ello haya lugar ${ }^{[22]}$. Es así como, la JEP propone un modelo procedimental híbrido entre lo adversarial y lo dialógico, según el grado de reconocimiento de verdad que otorguen las personas comparecientes (voluntarios o no), de modo que las víctimas pueden tener las prerrogativas propias de su calidad de intervinientes especiales cuando se trate de procedimientos adversariales, pero pueden llegar a tener un rol más amplio cuando se trate de procedimientos dialógicos ${ }^{[23]}$.

Adicionalmente, dentro de los principios de la JEP se establecen los enfoques diferenciales como prerrogativas o consideraciones especiales que otorga la normatividad procedimental en razón de la calidad particular de las víctimas, bien sea por su género u orientación sexual, por su pertenencia a un grupo étnico, o por su territorio, entre otras variables ${ }^{[24]}$. Se debe tener en cuenta que muchos de estos enfoques se aplican desde una perspectiva interseccional, es decir, que en una misma víctima o grupos de víctimas pueden confluir varios enfoques $^{[25]}$.

Para efecto de la participación, estos enfoques diferenciales se pueden interpretar como parámetros para agrupar a las víctimas y aplicar medidas especiales que faciliten su intervención en los procesos. Así, por ejemplo, hasta el momento el SAAD de la Secretaría Ejecutiva de la JEP ha representado a algunos colectivos étnicos, lo que significa que en virtud del enfoque étnico se ha decidido representar a las víctimas que hacen parte de estos grupos según su pertenencia a grupos indígenas y afrodescendientes ${ }^{[26]}$. Adicionalmente, respecto a los grupos étnicos, indígenas, afrodescendientes, raizales, palenqueras y Rrom, la normatividad de la JEP establece que tienen derecho a utilizar su lengua para participar en las diferentes fases de la JEP, por lo que esta Jurisdicción debe garantizar el acceso a traductores como parte de las medidas para facilitar su participación ${ }^{[27]}$. Respecto al enfoque territorial, vale la pena destacar que, si bien la JEP tendrá sede en Bogotá, la normatividad permite que sus salas y secciones sesionen en "cualquier lugar del territorio nacional para facilitar el acceso a la justicia a las víctimas" ${ }^{[28]}$. Es decir, se abre la posibilidad de descentralizar audiencias y diligencias, de modo que en términos prácticos la logística para que las víctimas asistan a las sesiones se facilitaría en gran medida.

\section{¿Quién tiene la calidad víctima ante la JEP y de qué manera pueden participar?}

En cuanto a quiénes pueden ser consideradas víctimas, cabe aclarar que la Ley de procedimiento de la JEP o Ley 1922 de 2018 (Ley de Procedimiento-JEP) no establece una definición en sentido estricto. Sin embargo, con base en los "Principios y directrices básicos sobre el derecho de las víctimas de violaciones manifiestas de las normas internacionales de derechos humanos y de violaciones graves del derecho internacional humanitario a interponer recursos y obtener reparacione." ${ }^{29]}$, la Corte Constitucional ha establecido que: víctima es

toda persona que haya sufrido daños, individual o colectivamente, incluidas lesiones físicas o mentales, sufrimiento emocional, pérdidas económicas o menoscabo sustancial de sus derechos fundamentales, como consecuencia de acciones $\mathrm{u}$ omisiones que constituyan una violación manifiesta de las normas internacionales de derechos humanos o una violación grave del derecho internacional humanitario. ${ }^{[30]}$ 
Además, según la Corte:

Cuando corresponda, y en conformidad con el derecho interno, el término "víctima" también comprenderá a la familia inmediata o las personas a cargo de la víctima directa y a las personas que hayan sufrido daños al intervenir para prestar asistencia a víctimas en peligro o para impedir la victimización. ${ }^{[31]}$

Conforme a esta definición, ante la JEP pueden participar víctimas directas o indirectas, y se tendrá en cuenta un espectro amplio de impactos y daños en diferentes niveles, lo que significa que, en principio, hay una apertura significativa para que las víctimas participen.

En cuanto a la forma en que las víctimas pueden acreditarse como intervinientes especiales en los procedimientos de la JEP, el art. 3 de la LP-JEP estipula que basta con que las víctimas presenten prueba siquiera sumaria de su condición, que puede ser el relato de las razones por las que la persona se considera víctima, especificando época y lugar de los hechos victimizantes. Adicionalmente, las víctimas indirectas deben demostrar su "interés directo y legítimo" para actuar en el caso al acreditar su condición ${ }^{[32]}$.

Las víctimas pueden actuar en las diferentes etapas y trámites procesales de la JEP en calidad de intervinientes especiales ${ }^{[33]}$. Aunque esta figura supone una diferencia sustancial entre la calidad de las víctimas y la calidad de otros sujetos procesales -como la persona compareciente, la defensa y la Unidad de Investigación y Acusación (UIA)-, el marco normativo de la JEP ha contemplado que las víctimas tengan prerrogativas casi a la par con otros sujetos en cuanto a los recursos judiciales que tienen a su disposición ${ }^{\text {[34] }}$. No obstante, el alcance de la participación de las víctimas depende de las diferentes etapas del proceso penal. ${ }^{[35]}$

Es importante destacar que, en virtud del principio dialógico, las víctimas tienen derechos de participación en la construcción de la verdad, y, por tanto, sus observaciones respecto al establecimiento de los compromisos concretos, claros y programados que deben cumplir los comparecientes en virtud del régimen de condicionalidad deben ser tenidas en cuenta ${ }^{[36]}$. Adicionalmente, las víctimas pueden presentar a la JEP informes sobre los hechos victimizantes que les han afectado a través de sus organizaciones como puerta de entrada a la misma, independientemente de que estén acreditadas ${ }^{[37]}$.

\section{Representación legal y asesoría jurídica}

Las víctimas acreditadas pueden actuar por sí mismas o a través de su representante lega ${ }^{[38]}$. Si bien aún no se ha estipulado con claridad en qué momentos pueden participar por sí mismas, se ha podido observar que, en el desarrollo de algunas diligencias, como las audiencias de condicionalidad que tuvieron lugar en 2018, algunas víctimas pudieron expresar sus opiniones directamente y de manera individual, en virtud del principio dialógico ${ }^{[39]}$.

Las víctimas tienen derecho a recibir asesoría, orientación y representación legal por parte de la JEP. Este derecho cobra especial relevancia cuando las víctimas no cuentan con los recursos económicos para contratar los servicios de un apoderado de confianza o no cuentan con el apoyo de una organización de víctimas que actúe con su anuencia para representar sus intereses ${ }^{[40]}$. En ese sentido, la JEP debe coordinar las acciones necesarias para garantizar la representación judicial con otras entidades y organismos públicos, bien sea a través del SAAD adscrito a la Secretaría Ejecutiva de la JEP, o a través del sistema de defensa pública ${ }^{[41]}$.

Para cumplir esta finalidad, el SAAD contrata los servicios de profesionales jurídicos para que asuman la representación de las víctimas acreditadas ante la JEP que no cuentan con los medios económicos para tal $\mathrm{fin}^{[42]}$. Es notable el esfuerzo que ha hecho el SAAD para que sean las mismas organizaciones de víctimas con experiencia y con enfoque territorial las que puedan prestar los servicios de representación ${ }^{[43]}$. 
Hasta agosto de 2019 la JEP ha representado a través del SAAD a 39 colectivos étnicos y alrededor de 127 víctimas individuales en todo el país ${ }^{[44]}$. De estos colectivos, 22 hacen parte del caso 004 sobre la situación territorial en la región de Urabá, y agrupan a 871 víctimas de las zonas humanitarias y de biodiversidad en dicha región ${ }^{[45]}$. No obstante, estos colectivos son resultado de procesos organizativos que ya estaban conformados y articulados para la defensa de sus derechos. Esto significa que hasta el momento el SAAD no ha tenido una demanda significativa de servicios de representación legal por parte de las víctimas, ni ha tenido que lidiar con la participación colectiva de víctimas que no estén articuladas en torno a su identidad étnica, por lo menos en lo concerniente a este caso. Sin embargo, como se explicará con más detalle a continuación, es probable que aumenten significativamente tanto las cifras de víctimas participantes, así como el número de víctimas que solicitan el servicio de representación legal gratuito, lo que hará que el rol del SAAD sea de gran relevancia para la participación de víctimas en los procedimientos.

\section{Macrovictimización y participación colectiva}

Como lo ha señalado la Corte Constitucional, la masividad de violaciones que son competencia de la JEP permite suponer que miles de víctimas pretendan participar ante esta jurisdicción. Tal participación masiva de víctimas implica una tensión entre dos derechos constitucionales de las mismas víctimas "el derecho de acceso a la administración de justicia y el derecho a obtener respuesta en un plazo razonable como parte del debido proceso" ${ }^{\text {[46] }}$, pues atender a todas las víctimas de manera individual sería un ejercicio imposible en el marco de la Justicia Transicional.

En este sentido, la Corte Constitucional ha señalado con relación a situaciones de macrovictimización que "una participación de las víctimas de carácter esencialmente individual llevaría al colapso del funcionamiento del SIVJRNR y en especial de la JEP"[47]. Sumado a ello, la Corte Constitucional ha indicado que la participación masiva podría poner en riesgo el principio de "igualdad de armas", lo que significa que se debe ponderar el derecho de las víctimas a participar y los derechos de los procesados ${ }^{[48]}$. La Sección de Apelaciones del Tribunal para la Paz de la JEP a su vez ha considerado que la participación directa e individual de todas las víctimas "podría entrar en tensión con [los] principios constitucionales de eficiencia, eficacia, celeridad y economía procesal”[49].

En virtud de estas consideraciones, tanto la Corte Constitucional como la JEP han privilegiado los mecanismos colectivos para que las víctimas puedan participar, aun cuando la normatividad contempla la posibilidad de participar de manera individual y directa. Teniendo en cuenta la estricta temporalidad que la JEP tiene para desarrollar su mandato en un plazo perentorio ${ }^{[50]}$, esta ha considerado que la participación colectiva tiene aptitud para imprimirle eficacia al proceso judicial y puede "reducir objetivamente el número de intervenciones y prevenir la repetición de solicitudes" ${ }^{\text {[51] }}$.

$\mathrm{Al}$ respecto, la normatividad procedimental establece que, si se trata especialmente de macrovictimización, la Sala o Sección del Tribunal para la Paz de la JEP donde se surte el trámite tiene la potestad de disponer que haya uno o más representantes comunes para que las víctimas actúen como uno o en varios grupos “a fin

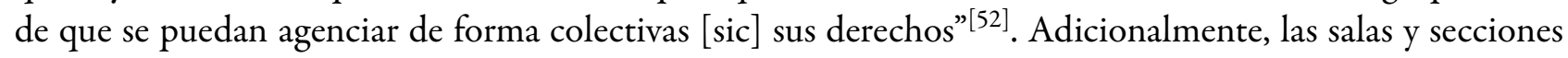
de la JEP pueden ordenar la acumulación de casos cuando hay identidad de partes, o cuando se identifican patrones de macrociminalidad ${ }^{[53]}$. Es decir, que aún en caso de que las víctimas puedan pagar su apoderado de confianza o que cuenten con una organización de víctimas que les brinde representación legal, en escenarios de masividad de víctimas la JEP puede disponer que estas se organicen como grupo para participar.

Sin embargo, hasta la fecha esta participación colectiva no ha tenido un despliegue significativo. En esta etapa temprana de funcionamiento de la JEP, el procedimiento que ha señalado la Secretaría Ejecutiva respecto a la designación de apoderado común para grupos de víctimas es el siguiente: 
- La Sala (o Sección) de la JEP profiere una orden para que el SAAD asigne un representante judicial a una o varias víctimas.

- El SAAD asigna un abogado de los adscritos, quien se encarga de comunicarse con las víctimas para determinar si están interesadas en participar ante la JEP y si carecen de recursos para costear su representación judicial.

- Si las víctimas confirman que desean contar con los servicios del SAAD, el abogado designado hace los trámites correspondientes para que se le reconozca como representante legal. ${ }^{[54]}$

Esto significa básicamente que, cuando se trata de víctimas determinadas, es la JEP la que ha venido activando los mecanismos para que el SAAD determine si estas desean participar y requieren un representante legal otorgado por el sistema. Adicionalmente, hasta el momento no existen limitaciones en cuanto al número de víctimas representadas por representante legal y tampoco existe un protocolo de comunicación y asesoría entre víctimas y representante legal ${ }^{[55]}$. No obstante, a partir de la SENIT 1, la Sección de Apelación del TP-JEP hizo un llamado a especificar y coordinar los mecanismos de participación colectiva, lo cual es una oportunidad para que se establezcan protocolos de asignación de representante legal más detallados, así como estándares mínimos respecto a cómo debe desarrollarse la asesoría legal ${ }^{[56]}$.

Además de las cuestiones sobre representación legal, la participación colectiva tiene otras aristas, en tanto la JEP considera a la participación colectiva como un "instrumento de cohesión social", el cual puede ser un mecanismo para adquirir y recopilar información estratégica ${ }^{[57]}$. De esta manera, la SENIT 1 de 2019 habla de la supra agencia, dando a entender que se trataría de un vocero de las víctimas que no tiene formación jurídica, pero que representaría a las víctimas en diligencias "que no ameriten defensa técnica" sentido, aún no hay una regulación específica de cómo las víctimas pueden designar a sus voceros y en qué momentos específicos estos las representarían.

Finalmente, cabe aclarar que la representación de las víctimas indeterminadas, es decir, de las víctimas que no se han podido localizar, notificar o identificar, está en cabeza del Ministerio Público, a saber: de la Procuraduría General de la Nación y la Defensoría del Pueblo. No obstante, el Ministerio Público también tiene el deber de promover mecanismos de participación colectiva de las víctimas determinadas, con el fin de que "de forma racional todas las víctimas puedan participar" [59].

\section{Otras experiencias de participación colectiva y lecciones aprendidas}

La participación colectiva de víctimas en tribunales internacionales y tribunales en contextos de justicia transicional es una tendencia inevitable que surge con la necesidad de dinamizar y hacer efectivos los procedimientos penales que han abierto la puerta a su participación. Sin embargo, la práctica en diferentes escenarios demuestra que existen grandes dificultades para implementar mecanismos de participación colectiva que preserven las posibilidades de que las víctimas sean escuchadas y tengan incidencia real en los procedimientos.

A ese respecto, algunas voces críticas señalan que la participación colectiva de víctimas en escenarios como la CPI y las ECCC termina por restringir las posibilidades de centralidad de las mismas. ${ }^{[60]}$ Entre las voces críticas, la de Christine Van den Wyngaert, ex magistrada del Tribunal Penal Internacional para la ExYugoslavia (TPIY), ex magistrada de la CPI y actualmente magistrada de las Salas Especializadas de Kosovo (KSC por sus siglas en inglés), llama especialmente la atención por su trayectoria en diferentes tribunales internacionales. Desde su experiencia en el TPIY que no contemplaba la participación de víctimas más allá del rol de testigos, pasando por la CPI, Van den Wyngaert encuentra que ante cantidades masivas de víctimas que deben ser representadas por apoderados comunes, aún si se logra coordinar que estos apoderados reciban instrucciones de todos o la mayoría de sus representados, es casi imposible que estas instrucciones 
puedan ser transmitidas en su totalidad a la Corte ${ }^{[61]}$ En ese sentido, plantea serios cuestionamientos sobre las posibilidades de que la participación colectiva de víctimas a través de representante legal común sea algo más que simbólica, y por ende, no pueda traducirse en una participación significativa para las víctimas ${ }^{[62]}$.

Sin embargo, desde la orilla de algunas organizaciones que trabajan con víctimas ${ }^{[63]}$, a pesar de las fallas y dificultades, los mecanismos de participación colectiva sí pueden llegar a brindar posibilidades de participación efectiva y significativa, siempre y cuando se tomen las medidas necesarias para que, a pesar de la mediación, las víctimas puedan ser escuchadas y tengan cierto margen de incidencia ${ }^{[64]}$.

En ese sentido, a continuación se identificarán algunas problemáticas y lecciones aprendidas de las experiencias de la CPI, las ECCC y los juicios de "Justicia y Paz", teniendo en cuenta las particularidades de sus enfoques procesales y contexto de funcionamiento.

\section{Participación colectiva en la Corte Penal Internacional}

En virtud del artículo 68 (3) del Estatuto de Roma, las opiniones y observaciones de las víctimas pueden ser presentadas y tenidas en cuenta en las diferentes fases del juicio a través de sus representantes legales si la Corte lo considera conveniente, es decir, la especificidad de los momentos y modalidades de su participación queda a discreción de lo que los jueces decidan ${ }^{[65]}$. Las víctimas son consideradas participantes, pero no tienen estatus de "parte" dentro de los procedimientos, teniendo en cuenta que el proceso ante la CPI tiene una gran influencia del sistema acusatorio ${ }^{[66]}$.

Si bien ha habido participación directa y presencial de víctimas como testigos, en la práctica solo los representantes legales de las víctimas atienden a las audiencias y diligencias que se desarrollan en la CPI, cuando hay lugar a ello. ${ }^{[67]}$ Teniendo en cuenta que las víctimas se encuentran en su gran mayoría en países a miles de kilómetros alejados de la sede de la CPI en la Haya, la participación indirecta de las víctimas en los procedimientos es la norma, y por ello, bajo estas circunstancias la persona que funge como representante legal es la voz de las víctimas ante la CPI ${ }^{[68]}$. De esta manera, el representante legal tiene un doble rol que impone grandes responsabilidades: por una parte, debe consultar y entender las preocupaciones y observaciones de las víctimas para poderlas presentar ante la corte, y por otra, debe informar a las víctimas acerca de los procedimientos, los avances, las dificultades, y sobre todo sobre las expectativas racionales que se pueden generar $^{[69]}$.

En ese sentido, uno de los aspectos problemáticos de la participación colectiva ha sido la escogencia de representante legal para las víctimas. Si bien la Regla 90 de las Reglas de Procedimiento y Evidencia de la CPI (RPP-CPI) estipula que la víctima puede escoger libremente a su representante, en caso de pluralidad de víctimas la CPI puede pedirles que nombren uno o más representantes comunes. De manera excepcional, si las víctimas no pueden elegir dentro del plazo que fije la Sala correspondiente, será la Secretaría de la CPI quien tome esta decisión.

En el caso Lubanga, el primer caso que abrió la CPI, hubo un número de víctimas manejable (129 víctimas), así que se permitió a estas escoger a sus representantes legales. Las víctimas fueron organizadas en dos grupos representadas por dos equipos de representantes, entre externos y los provistos por la Oficina de Asistencia Pública para Víctimas ${ }^{[70]}$. Sin embargo, en casos posteriores el número de víctimas incrementó considerablemente y no solo se implementó la participación colectiva, sino que el proceso de dar oportunidad primero a las víctimas para escoger a su representante legal común fue obviado, y en general las Salas de la CPI han puesto en manos de la Secretaría esta decisión, dejando a su vez muy poco o ningún margen de acción a las víctimas ${ }^{[71]}$.

Aunque las dificultades logísticas y de recursos económicos que implica consultar con las víctimas parecen ser argumentos convincentes para prescindir de su opinión ${ }^{[72]}$, según varios expertos y organizaciones de 
víctimas esta decisión puede traer consecuencias contraproducentes de cara a la participación efectiva y significativa de las víctimas ${ }^{[73]}$. En primer lugar, se está partiendo de la presunción de que de las víctimas son incapaces de tomar estas decisiones, $\mathrm{y}$, sin embargo, muchas veces el problema para la toma de decisiones por parte de las víctimas puede radicar más bien en la falta de información ${ }^{[74]}$. Por otra parte, si la satisfacción de las víctimas participantes de la CPI depende en gran medida de la interacción con sus representantes legales, es importante que estas tengan un mínimo de incidencia en la escogencia de los mismos ${ }^{[75]}$. Además, la imposición unilateral de representantes legales puede significar rupturas innecesarias cuando ya se han establecido relaciones de confianza cliente-apoderado ${ }^{[76]}$. Así, por ejemplo, en el caso Banda y Jerbo las víctimas reclamaron por la decisión de la CPI de excluir a los abogados con quienes venían trabajando, y solicitaron que se les informara sobre los argumentos que tuvo la Secretaría para nombrar otros representantes legales, pues ya habían establecido una relación de confianza con los abogados que habían escogido ${ }^{[77]}$.

Otro gran reto, objeto de críticas e inconformidades por parte de las víctimas, tiene que ver con la comunicación con sus representantes legales. En general, el personal de la CPI debe viajar a los territorios donde se encuentran las víctimas, y, sin embargo, se ha utilizado la figura de los intermediarios para coordinar la comunicación entre las víctimas y la Corte ${ }^{[78]}$. Según un estudio de la ONG REDRESS, que se basa en la opinión de las víctimas, concluye que la comunicación y consulta con sus representantes legales en el contexto de la CPI es aún insuficiente. Incluso hay víctimas que nunca han conocido a su apoderado ${ }^{[79]}$. La ausencia de una comunicación periódica ha generado en algunos casos desconfianza y falta de credibilidad en la CPI por parte de las víctimas ${ }^{[80]}$.

Esta situación, sin embargo, no recae únicamente en la responsabilidad de los representantes legales, pues existen dificultades prácticas evidentes para consultar a cientos o miles de víctimas y al mismo tiempo hay limitados recursos financieros y humanos para tales fines ${ }^{[81]}$. En el caso Bemba Gombo, por ejemplo, 5229 víctimas participantes fueron representadas por un equipo de cinco personas, lo cual evidentemente demuestra un desbalance tal que las capacidades de los representantes fueron sobrepasadas ${ }^{[82]}$.

Como lo señala la Federación Internacional por los Derechos Humanos (FIDH), una de las claves para lograr consultar adecuadamente a las víctimas son los encuentros con grupos más pequeños de las mismas, ante las dificultades de consultarlas individualmente ${ }^{[83]}$, esto, sin descartar la posibilidad de encuentros individuales en casos excepcionales en los que se discuten cuestiones especiales o confidenciales. Sumado a ello, los canales de comunicación remota como el teléfono, y el email son una opción importante cuando no se pueden hacer encuentros frecuentes o es difícil reunir a las víctimas para este fin ${ }^{[84]}$. De todas maneras, estos encuentros deben tener en cuenta las costumbres y prácticas culturales de las comunidades, como se planteó en el caso Kenya $\mathrm{II}^{[85]}$.

Finalmente, los criterios de agrupación de víctimas son otro aspecto problemático, especialmente cuando se agrupa un alto número de víctimas bajo la misma representación legal. La misma normatividad que regula la participación de las víctimas reconoce que al colectivizar la participación puede haber conflictos de intereses ${ }^{[86]}$, y por eso se debe procurar que los diferentes intereses de las víctimas se vean efectivamente representados. Sin embargo, cuando las víctimas son agrupadas en miles, como en el caso Bemba (5229 víctimas), surgen muchas dificultades para tal fin. En este caso el criterio geográfico fue tomado en cuenta para agrupar a las víctimas, de manera que víctimas miembros de la misma familia o comunidad fueran representadas por el mismo representante legal ${ }^{[87]}$. Sin embargo, tal decisión fue criticada por la ONG Women'sInitiative on Gender Justice, pues el criterio geográfico desconocía los intereses específicos de las víctimas de violencia sexual, especialmente por el gran número de víctimas agrupadas ${ }^{[8]}$. En cierta medida, esta crítica ejemplifica que las tensiones por los criterios de agrupación se relacionan también con la posibilidad de escoger un representante legal de confianza o con experiencia para representar los intereses específicos de las víctimas ${ }^{[89]}$. Adicionalmente, la estigmatización que pueden sufrir las víctimas de violencia 
sexual dentro de sus comunidades e incluso dentro de su círculo familiar es un argumento de fondo para que se prefiera que las víctimas de violencia sexual no sean agrupadas con víctimas de otros crímenes ${ }^{[90]}$.

\section{Participación colectiva ante las Salas Extraordinarias de las Cortes de Camboya}

A diferencia de la CPI, la sede de las ECCC se encuentra en el mismo país donde ocurrieron los hechos victimizantes, y donde se encuentran la mayoría de las víctimas participantes. Por otra parte, el régimen de participación ante las ECCC está planteado de una manera más amplia que ante la CPI, ya que las víctimas pueden participar como partes civiles ${ }^{[91]}$. Es decir, las víctimas tienen, en teoría, el derecho a participar en todas las fases de los procedimientos al mismo nivel de la Fiscalía y la Defensa, además de los derechos que les conciernen en procedimientos para obtener reparaciones ${ }^{[92]}$. No obstante, una de las grandes fallas del diseño de la participación de las víctimas ante las ECCC es que no se previó inicialmente presupuesto ni oficina o sección para la representación de las partes civiles ${ }^{[93]}$. El pago de la gran mayoría de representantes legales de víctimas se ha logrado a través del apoyo de gobiernos extranjeros y a través de la modalidad pro bono ${ }^{[94]}$. En la práctica, la representación legal de las partes civiles ha estado predominantemente a cargo de ONGs con presencia en territorio, lo cual ha facilitado hasta cierto punto la comunicación con las víctimas y su agrupación ${ }^{[95]}$.

En el primer caso abierto por las ECCC, el caso Duch (Caso 001), participaron 93 partes civiles a través de sus representantes legales. Las víctimas fueron organizadas en cuatro grupos de partes civiles, con un equipo de dos abogados por cada grupo (uno nacional y uno internacional) ${ }^{[96]}$. La colaboración entre los diferentes equipos fue compleja, ya que a pesar de que en términos generales todos tenían el mismo objetivo, había desacuerdos en las estrategias legales, así como en cuestiones procedimentales y legales ${ }^{[97]}$. Adicionalmente, la falta de coordinación entre los representantes legales trajo como consecuencia que los interrogatorios a testigos fueran repetitivos y muy largos ${ }^{[98]}$.

En el Caso 002 participaron 3866 víctimas como partes civiles, y dado el aumento significativo de víctimas participantes, y las dificultades de coordinación que también se dieron en el caso 001 , se pasó a un enfoque eminentemente colectivo de participación de las víctimas. ${ }^{[99]}$ A través a una enmienda a las reglas internas se estableció que la parte civil podía actuar a través de sus propios representantes legales en la etapa de investigación, pero a partir de la etapa de juicio las partes civiles debían actuar como un solo grupo consolidado que debía ser representado ante las ECCC por dos coabogados líderes (Civil Party Lead Co-Lawyers). ${ }^{[100]}$ Estos coabogados son seleccionados y pagados por las ECCC, uno es nacional y el otro internacional, y solo a través de ellos las víctimas tienen derecho a ejercer las prerrogativas de la parte civil. Es decir que, aun si las víctimas conservan sus representantes legales, solo estos coabogados líderes pueden actuar en nombre y representación de las víctimas como un grupo consolidado ante las ECCC. Dentro de sus deberes como coabogados líderes está el de coordinar la representación con las partes civiles, por ende, con sus representantes legales, y tratar de alcanzar consensos ${ }^{[101]}$. Asimismo, se establece que haya una sola petición para reparaciones morales y colectivas que incluya a todas las partes civiles como un grupo ${ }^{[102]}$.

Así como en el contexto de la CPI, la reducción del margen de incidencia de las víctimas en la escogencia de su representante legal es una de las problemáticas que se pueden identificar. Especialmente porque las víctimas son obligadas a consolidarse como un solo grupo a partir de la etapa de juicio, y aún si pueden conservar su abogado de confianza, solo pueden actuar ante las ECCC a través de los coabogados líderes de la parte civil que proveen las ECCC ${ }^{[103]}$. Entonces, cabe preguntarse hasta qué punto el interés de miles de víctimas puede reducirse a una voz común representada por un abogado que ni siquiera han escogido. Evidentemente, 
el criterio de participación colectiva de las ECCC genera graves preocupaciones respecto a las posibilidades que tendrían víctimas o grupos de víctimas con intereses u opiniones divergentes para expresar su voz en los procedimientos ${ }^{[104]}$. Sumado a ello, otra problemática que plantea este esquema de participación colectiva es que realmente no hay una relación cliente-apoderado entre las víctimas y los abogados líderes, pues estos últimos tienen contacto con los representantes legales de las víctimas, pero no tienen contacto directo con estas.

En la práctica, estas preocupaciones han sido relativizadas hasta cierto punto, ya que en algunas ocasiones los coabogados líderes han permitido a los representantes legales de las partes civiles intervenir directamente ante la corte, interrogando testigos, presentando documentos e incluso declaraciones de cierre

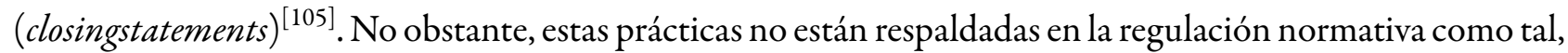
y dependen de la voluntad de los coabogados líderes.

Finalmente, cabe aclarar que, aunque la asistencia de las víctimas como partes civiles a las audiencias de la corte es permitida, en la práctica ha demostrado ser costosa y difícil. Si bien tanto víctimas como corte se encuentran en el mismo país, algunas víctimas viven fuera de la ciudad Phnom Pehn, lugar sede de las ECCC. Como consecuencia, se observó en los procedimientos del Caso 001 que la asistencia de víctimas fue baja, y aunque la Corte ha adoptado algunas medidas para facilitar la asistencia de las víctimas, teniendo en cuenta la masividad de partes civiles, es evidente que las restricciones presupuestales no permitirían que la Corte financiara a todas ellas la asistencia a las audiencias ${ }^{[106]}$. Por lo tanto, la transmisión de las audiencias ha sido la estrategia más utilizada para que las víctimas y en general la sociedad civil pueda estar enterada de lo que sucede en estas diligencias ${ }^{[107]}$.

\section{Participación colectiva en los procedimientos penales de "Justicia y Paz" en Colombia}

En Colombia, el antecedente más reciente de la JEP, en perspectiva de Justicia Transicional, es la experiencia que ha tenido lugar en el marco de la Ley 975 de 2005 o Ley de Justicia y Paz, en virtud de la cual se juzgarían los crímenes de los desmovilizados, especialmente paramilitares, después del proceso de paz con este grupo.

Los juicios de "Justicia y Paz" se enmarcan dentro de la jurisdicción penal ordinaria, aunque caracterizados por un procedimiento especial estructurado para facilitar la desmovilización y dejación de armas de ex combatientes ${ }^{[108]}$. Las víctimas como participantes en los procedimientos penales tienen estatus de "intervinientes especiales" y sus derechos y prerrogativas se rigen por los parámetros ya establecidos en el Código de Procedimiento Penal (Ley 906 de 2004) y los desarrollos a nivel jurisprudencial, que otorgan un papel protagónico a las víctimas ${ }^{[109]}$. En ese sentido, la Ley 1592 de 2012, por la cual se modifican algunos artículos de la Ley de Justicia y Paz, establece que las víctimas pueden actuar directamente o por medio de su representante en todas las etapas del proceso $^{[110]}$, y estipula que la participación de las víctimas debe desarrollarse en atención a enfoques diferenciales ${ }^{[111]}$.

Las víctimas tienen derecho a contar con representante legal, de manera que, si no tienen los recursos económicos para pagar los servicios de un abogado, las Fiscalía General de la Nación debe designarles uno de oficio $^{[12]}$. A diferencia de la JEP, para los procedimientos de Justicia y Paz no se creó una sección especial como el SAAD, y en la práctica la Defensoría del Pueblo ha asumido la representación de las víctimas determinadas que no cuentan con apoderado de confianza y la Procuraduría ha representado a las víctimas no determinadas.

Respecto a la participación colectiva, la normatividad prevé que si hay pluralidad de víctimas que desean participar en la diligencia de las versiones libres ${ }^{[13]}$, estas pueden designar hasta dos abogados que las representen, y si no pueden llegar a un acuerdo, la Fiscalía tomará la decisión ${ }^{[114]}$. En ese sentido, la participación colectiva de víctimas se ha implementado parcialmente en esta diligencia, pues en ciudades 
diferentes a Bogotá en algunas ocasiones no se ha designado a los dos representantes legales comunes, sino que cada uno de los defensores presentes ha podido intervenir ${ }^{[115]}$.

En términos generales, una de las problemáticas más graves que se ha podido identificar respecto a la participación colectiva de víctimas está relacionada con el desbalance entre número de representantes legales y número de víctimas representadas. Los abogados que provee la Defensoría del Pueblo son insuficientes para la cantidad de víctimas que requieren sus servicios, y por tanto estas asignaciones terminan por sobrepasar sus capacidades. Esto tiene repercusiones en las posibilidades de comunicación y consultación entre víctimas y representantes legales, y en la cantidad y calidad de información que reciben las víctimas ${ }^{[116]}$.

Para el 30 de mayo de 2009, 60 defensores representaban a 6000 víctimas en Bogotá, 28 defensores representaban a 12.977 víctimas en Barranquilla, y 21 defensores representaban a 21.500 víctimas en Medellín ${ }^{[17]}$. Algunas víctimas que lograron ser representadas nunca hablaron con sus representantes legales, o solo pudieron conversar vía telefónica con sus abogados ${ }^{[118]}$. Para el año 2017 se registró un número mayor de víctimas representadas mientras el número de defensores públicos no aumentó significativamente, pues 32.226 víctimas de Antioquia eran representadas por 33 defensores, 17.500 víctimas en Atlántico eran representadas por 29 defensores, y 17.000 víctimas en Bogotá eran representadas por 40 defensores ${ }^{[119]}$.

La participación en tales condiciones podría calificarse como apenas simbólica, pues en la práctica muchas víctimas no tuvieron voz ni posibilidad de incidencia en los procesos. Este es un factor que ha generado desinterés en las víctimas de Justicia y Paz para participar en las versiones libres, y que se refleja en el hecho de que hay una participación de víctimas decreciente en esta diligencia desde $2012^{[120]}$. En ese sentido, varios sectores de las víctimas que han participado en los procedimientos de Justicia y Paz han considerado que su rol de víctimas ha sido instrumentalizado en el discurso para legitimar el marco jurídico, y no ven en la práctica que estos derechos de participación de las víctimas se hayan cumplido a satisfacción ${ }^{[121]}$.

En términos generales, dada la gran cantidad de víctimas participantes en los procesos y teniendo en cuenta que la gran mayoría de las víctimas no tiene recursos para pagar a un abogado de confianza, el sistema de representación legal gratuito ofrecido por la Defensoría del Pueblo se ha mostrado insuficiente y es foco de diversas problemáticas ${ }^{[122]}$. Así, por ejemplo, algunas víctimas conocieron a su representante legal directamente en las versiones libres y en algunos casos se ha implementado un sistema rotativo de representación, lo cual impide a todas luces que se pueda establecer una relación fluida de comunicación y consulta entre víctimas y abogados. En algunos de los casos, esto degenera en que los representantes legales desconocen información importante que bien podría haber sido provista por las víctimas ${ }^{[123]}$.

Por otra parte, para facilitar la participación masiva de víctimas en las diligencias de versión libre, se han realizado alrededor de 8251 transmisiones en directo en los municipios de residencia de las víctimas, cuando a ello hay lugar, evitando las complicaciones y costos de desplazamiento hacia las ciudades en las que tienen lugar las diligencias ${ }^{[124]}$. Sin embargo, dado el esfuerzo logístico que significa organizar estas transmisiones y que las víctimas puedan asistir, es una falla notoria que la Fiscalía en varias ocasiones haya citado a las víctimas a diligencias de manera equivocada, pues su caso no fue tratado en el desarrollo de las mismas ${ }^{[25]}$. También se han presentado casos en que problemas técnicos han impedido la retransmisión de las versiones libres ${ }^{[126]}$.

\section{Desafíos para concretar parámetros regulatorios de la participación colectiva en la JEP}

Dado que la JEP está aún en una etapa inicial de funcionamiento, la participación colectiva no ha sido uno de los principales desafíos que haya tenido que enfrentar esta jurisdicción hasta el momento. Aún son relativamente pocas las víctimas acreditadas, y no se ha requerido organizar a las víctimas en grupos para la participación en las etapas procesales que ya se vienen desarrollando, tales como las audiencias de 
condicionalidad o las versiones voluntarias de los comparecientes. Sin embargo, este panorama está próximo a cambiar. Hasta el 14 de noviembre de 2019 se habían acreditado 1276 víctimas en el caso $001^{[127]}$, y ya han empezado los procesos de acreditación de los casos 004 (situación de Urabá) ${ }^{[128]}$ y 005 (situación territorial del Norte del Cauca y Sur del Valle del Cauca) ${ }^{[129]}$. Por tanto, se espera se aborden ciertos desafíos para poder coordinar los mecanismos de participación colectiva de cientos o incluso miles de víctimas ${ }^{[130]}$.

Adicionalmente, se espera que haya víctimas acreditadas que requieran servicios de representación legal gratuita, dado que los hechos victimizantes se han enfocado particularmente en la población más vulnerable y marginada a nivel socio-económico ${ }^{[131]}$, teniendo en cuenta que especialmente el desplazamiento forzado ha traído como consecuencia la pauperización del nivel de vida de muchas víctimas ${ }^{[132]}$.

A partir de estas consideraciones y del análisis desarrollado previamente, se expondrán a continuación algunos desafíos específicos que deben ser tenidos en cuenta a la hora de establecer los parámetros que regulan la participación colectiva de víctimas en la JEP.

\section{Excepciones a la participación colectiva}

Como se ha puesto de presente con las críticas que surgen de las experiencias de la CPI, las ECCC y Justicia y Paz, la participación colectiva conlleva ciertos riesgos. En este sentido, la Corte Constitucional y la JEP, citando al relator de las Naciones Unidas sobre la promoción de la verdad, la justicia, la reparación y las garantías de no repetición, reconocen el riesgo de la homogenización de la victimización y de los intereses de las víctimas que desean participar, dando como resultado efectos no deseados, como son las luchas de las víctimas por diferenciarse ${ }^{[133]}$.

La JEP ha señalado a este respecto que las víctimas no pueden ser obligadas a asociarse, ya que su participación debe ser siempre voluntaria. De esta manera, se reconoce que en ciertas circunstancias las víctimas podrán actuar de forma individual siempre y cuando medie una solicitud suficientemente sustentada y "no se pongan en riesgo otros derechos fundamentales y la eficacia del sistema" ${ }^{[134]}$. Así, por ejemplo, la necesidad de protección de la intimidad es una de las motivaciones para permitir intervenciones individuales o el hecho de que en ciertas diligencias se requiera la manifestación de una o pocas víctimas ${ }^{[35]}$

Aunque a nivel jurisprudencial se ha hecho este reconocimiento, aún hace falta regular de manera más concreta los criterios para admitir de manera excepcional que las víctimas puedan actuar de forma individual o en grupos más pequeños.

\section{Criterios de agrupación y elección de representante legal}

Como se ha explicado, la decisión sobre la agrupación de las víctimas y la elección de un representante común recae en la JEP. No obstante, aún no hay claridad sobre cuáles son los criterios de agrupación que deben tenerse en cuenta, ni tampoco sobre cuál es la capacidad de incidencia de las víctimas en la forma de agrupación y en la elección del representante legal. Es necesario tener en cuenta que los enfoques diferenciales, como aspecto transversal de todo el modelo de Justicia Transicional actual, imponen consideraciones especiales que también tienen resonancia en las formas de agrupación de las víctimas. Sumado a ello, es necesario establecer parámetros no solo en la forma de agrupación de las víctimas, sino también en el balance cuantitativo entre el número de víctimas por representante legal, pues de esto depende que no se sobrepasen las capacidades del mismo, de manera que le imposibilite mantener canales de comunicación adecuados con las víctimas, como ha sucedido en la experiencia de Justicia y Paz.

Finalmente, si bien el SAAD de la JEP está haciendo esfuerzos importantes para que organizaciones de víctimas y de derechos humanos que ya tienen experiencia con la representación de víctimas con enfoques 
diferenciales puedan asumir representación gratuita de víctimas ante la JEP, es importante que estas puedan tener cierta incidencia en la escogencia. Como se ha puesto de presedente en las críticas a los modelos de participación colectiva de la CPI y las ECCC, este mínimo de incidencia redunda no solo en que las víctimas se sientan tenidas en cuenta, sino que puede facilitar que se establezcan lazos de confianza entre víctimas y el representante legal. En el contexto de la JEP, dentro de las opciones que brinda la base de datos del SAAD, podría abrirse, por ejemplo, la posibilidad de que las víctimas indiquen sus preferencias, aunque sea esta jurisdicción la que tenga la última palabra. También debería abrirse aquella posibilidad de cambiar de representante si las víctimas consideran que la persona designada por la JEP no tiene las calidades necesarias para representarlas.

\section{Comunicación y consulta con las víctimas}

Teniendo en cuenta las dificultades de movilidad y seguridad para las víctimas que residen en regiones diferentes a Bogotá, es necesario establecer cómo será la comunicación y cómo se harán las reuniones que permitirán mantener a las víctimas informadas sobre el desarrollo de sus procesos, y a su vez permitirán al representante legal recopilar las consideraciones, intereses y necesidades de las víctimas para ser transmitidas ante la JEP. Especialmente, las críticas a las experiencias de la CPI y Justicia y Paz demuestran la importancia de una comunicación previa a las actuaciones procesales entre víctimas y representante legal, y la necesidad de tener diferentes opciones para que esta comunicación sea fluida. En ese sentido, es importante que haya regularidad en esta comunicación y que las víctimas tengan posibilidad de contactar a sus representantes cuando lo consideren necesario, además de las reuniones presenciales.

\section{Principio dialógico y participación colectiva}

Finalmente, un desafío fundamental que no tiene un referente explícito en los escenarios planteados en la sección anterior, y que se debe tener en cuenta en la concreción de la regulación de la participación colectiva está relacionado con el principio dialógico. La Sala de Reconocimiento de Verdad y Responsabilidad (SRVR) de la JEP ha establecido que el principio dialógico implica la "interlocución directa entre víctimas y comparecientes que promuevan el reconocimiento y superen en alguna medida la lógica propia de instancias judiciales ordinarias de tipo puramente adversarial" ${ }^{[136]}$. Como ya se ha mencionado, el procedimiento dialógico se aplicará de prevalencia, especialmente en los casos de reconocimiento de verdad.

No obstante, frente al planteamiento de una interlocución directa entre víctimas y comparecientes cabe preguntarse ¿cómo puede tener lugar un diálogo entre cientos o incluso miles de víctimas y los victimarios?; ¿a través de representante legal o a través de ciertas víctimas que ejercen esta llamada supra agencia?

Hasta el momento, una respuesta parcial a estas preguntas que se ha dado con respecto a las versiones libres de las personas comparecientes ante la SRVR. Si bien en principio, no era posible la participación de las víctimas en estas diligencias, tras una decisión de la SRVR se ha ampliado la participación de las víctimas en las versiones voluntarias en el caso 003, conforme al artículo 27 de la LPE-JEP, que permite adoptar las medidas necesarias para promover la construcción dialógica de la verdad ${ }^{[137]}$. Esta ampliación se hizo a condición de que se tengan en cuenta ciertas pautas para limitar la presencia de representantes legales en virtud del principio de igualdad de armas ${ }^{[138]}$, así como ciertas pautas para preguntar al compareciente y para preparar a las víctimas desde un punto de vista psicosocial y procedimental ${ }^{[39]}$. Es decir, las víctimas no tendrían un contacto directo con los comparecientes.

Sin embargo, también se han realizado audiencias con participación directa de las víctimas. Así, por ejemplo, el 17 de octubre de 2019 se celebró la primera audiencia pública en la que se escucharon las 
observaciones de 13 víctimas del Caso 003 respecto a las versiones voluntarias de comparecientes. Fue notorio que las víctimas hablaron directamente sin mediación de sus abogados y presentaron no solo sus observaciones sino sus historias y emociones durante una audiencia que tuvo una duración de, aproximadamente, 7 horas $^{[140]}$.

Precisamente, la aplicación del principio dialógico como un diálogo directo con las víctimas es uno de los desafíos, pues de sacrificarse totalmente esta posibilidad en nombre de la eficacia, se podría estar desnaturalizando el enfoque restaurativo y dialógico de la JEP. No obstante, cuando se piense en participación masiva de víctimas, seguramente será necesario plantear alternativas para dar lugar a un diálogo con las víctimas. Bien sea desde la figura de la supra agencia, es decir, que las víctimas designen a un representante o subgrupo representativo, o a través de otro tipo de actos simbólicos en los que se pueda incluir a cientos o miles de víctimas, de manera que las capacidades de la JEP no se desborden y no se ponga en riesgo el avance de los procedimientos en detrimento de las víctimas mismas.

\section{Conclusiones}

Ante la inminencia de poner en práctica mecanismos de participación colectiva a través de representación legal común para facilitar la participación masiva de víctimas en la JEP, es necesario tener presente los riesgos y desafíos que pueden conllevar consecuencias no deseadas en perjuicio de las víctimas y del funcionamiento y legitimidad de esta jurisdicción. En ese sentido, la necesidad de hacer procedimientos expeditos y de economizar recursos humanos y financieros no puede sacrificar innecesariamente las posibilidades de una participación significativa para las víctimas.

A lo largo del artículo se han identificado riesgos de la participación colectiva tales como la homogenización de las víctimas, la sobrecarga de los representantes legales, la falta o deficiente comunicación y consulta entre víctimas y representantes legales, así como las dificultades para establecer relaciones de confianza entre las víctimas y los representantes, entre otros. En la práctica, estos factores de riesgo pueden resultar en una participación de víctimas meramente simbólica.

No obstante, estos riesgos se pueden minimizar a través de diferentes medidas. Así, por ejemplo, se puede evitar la sobrecarga de los representantes legales si hay un staff suficiente de estos que puedan ser proporcionados de manera gratuita a las víctimas. Esto requiere, sin embargo, que se disponga del presupuesto necesario para subvencionar una representación legal de calidad.

Aunado a ello, debe permitirse unos mínimos de incidencia de las víctimas en aspectos esenciales como la elección de su representante legal. Bien sea de manera previa o posterior, es importante que las víctimas tengan un margen de incidencia, y aunque la última palabra recaiga en la institucionalidad y no en ellas, estas decisiones deben ser explicadas y sustentadas debidamente. De la misma manera, es importante que se tengan en cuenta los enfoques diferenciales al agrupar a las víctimas, y que haya excepciones a la participación colectiva que permitan que en algunas ocasiones las víctimas puedan actuar de manera individual.

Finalmente, cabe reconocer que los tribunales penales tienen limitaciones. Además de las cuestiones presupuestales, los componentes judiciales en contextos de justicia transicional no pueden abarcar todas las necesidades de las víctimas, sino algunos aspectos de lo que se ha considerado fundamental para su reconocimiento y empoderamiento. En ese sentido, es importante que haya transparencia con las víctimas respecto a lo que pueden y no pueden esperar de los procedimientos penales y de su participación en estos escenarios. En el caso específico de la JEP, es importante que se aclare a las víctimas y a la sociedad en general que no todas las víctimas podrán participar en los procedimientos, y que la participación tiene otras manifestaciones más allá de las audiencias y demás diligencias de la JEP. La participación de víctimas tiene lugar en la elaboración y presentación de informes, se materializa también en la asesoría legal y psicológica, y puede cobrar sentido en actividades y encuentros extrajudiciales dentro del SIVJRNR. 
Aún está por verse cómo se desarrollará la participación masiva de víctimas ante la JEP, y por ello, aún pueden tomarse medidas para evitar falencias de otras experiencias o por lo menos minimizar su impacto, sin embargo, no se puede dar respuesta anticipada a todos los desafíos que están por venir. Por otra parte, la discusión sobre la participación significativa y efectiva de las víctimas en escenarios de justicia transicional y derecho penal internacional sigue abierta, pues las voces críticas de las experiencias de la CPI, las ECCC y Justicia y Paz parecen indicar que las promesas iniciales en torno a la participación de las víctimas no se han podido cumplir todavía, y difícilmente se cumplirán a cabalidad. Ante este panorama, es necesario buscar caminos diferentes a la participación de víctimas en procedimientos penales para satisfacer sus derechos, sin embargo, para ello sería importante indagar a fondo qué piensan y quieren las víctimas.

\section{Bibliografía}

Acto Legislativo 01 de 2017, por medio del cual se crea un título de disposiciones transitorias de la Constitución para la terminación del conflicto armado y la construcción de una paz estable y duradera y se dictan otras disposiciones. 4 de abril de 2017. D. O. 50196.

Alain Werner \& Daniella Rudy, Civil party representation at the ECCC: Sounding the retreat in international criminal law, 8 Northwestern Journal of International Human Rights, n. ${ }^{\circ}$ 3, 301-309 (2009). https://scholarlycommon s.law.northwestern.edu/njihr/vol8/iss3/4/

Alexa Koenig, Eric Stover, Stephen Smith \& Mychelle Balthazard, The Victims Court: A Study of 622 Victim Participants at the International Criminal Court (Human Rights Center, University of California, 2015). https ://www.law.berkeley.edu/wp-content/uploads/2015/04/The-Victims-Court-November-2015.pdf

Andreas Forer, La participación de las víctimas en el marco de un proceso de justicia transicional - el caso colombiano en la Ley de Justicia y Paz, en Participación de las víctimas en la Ley de Justicia y Paz y Corte Penal Internacional, 48-49 (Claudia López Díaz Comp., Giz, 2011). https://www.jep.gov.co/Sala-de-Prensa/Documents/GTZ\%2 0\%20CARTILLA\%20V\%C3\%8DCTIMAS.pdf

Angélika Rettberg, Reparación en Colombia ¿Qué quieren las víctimas?, 9 (Agencia de Cooperación Técnica Alemana, GTZ, 2008)

Anushka Sehmi, Now that we have no voice, what will happen to us?': Experiences of Victim Participation in the Kenyatta Case, 16 Journal of International Criminal Justice, $571-591$ (2018). https://doi.org/10.1093/jicj/mq y024

Binxin Zhang, Recognizing the Limits of Victims Participation: A Comparative Examination of the Victim Participation Schemes at the ECCC and the ICC, en The Extraordinary Chambers in the Courts of Cambodia, 515-534 (Simon M. Meisenberg \& Ignaz Stegmiller eds., Springer, 2016).

Brianne McGonigle Leyh, Procedural Justice? Victim participation in international criminal proceedings (Intersentia, 2011).

Charles P. Trumbull IV, The Victims of Victim Participation in International Criminal Proceedings, 29 Michigan Journal of International Law, n. ${ }^{\circ}$ 4, 777-826 (2008). https://repository.law.umich.edu/mjil/vol29/iss4/4/

Christine Van den Wyngaert Hon, Victims Before International Criminal Courts: Some Views and Concerns of an ICC Trial Judge, 44 Case Western Reserve Journal of International Law, n. ${ }^{\circ}$ 1, 475-496 (2011). https://scholarlycom mons.law.case.edu/cgi/viewcontent.cgi?article $=1102 \&$ context $=$ jil

Contraloría General de la República, Análisis sobre los resultados y costos de la Ley de Justicia y Paz (2017). https://www.contraloria.gov.co/documents/20181/466201/An\%C3\%A1lisis+sobre+los+resultados $+\mathrm{y}+$ costos $+\mathrm{de}+\mathrm{la}+\mathrm{Ley}+\mathrm{de}+\mathrm{Justicia}+\mathrm{y}+\mathrm{Paz} / \mathrm{dcce} 2907-\mathrm{f} 669-42 \mathrm{~b} 8-8857-7 \mathrm{e} 14750 \mathrm{cc} 467$ ?version=1.0

Corte Constitucional de Colombia. Auto 004 de 2009 (M. P. Manuel José Cepeda Espinosa; 26 de enero de 2009).

Corte Constitucional de Colombia. Sentencia C-080 de 2018 (M. P. Antonio José Lizarazo, 15 de agosto de 2018).

Corte Constitucional de Colombia. Sentencia C-228 de 2002 (M. Ps. Manuel José Cepeda Espinosa, Eduardo Montealegre Lynett; 3 de abril de 2002). 
Corte Constitucional de Colombia. Sentencia C-370 de 2006 (M. Ps. Manuel José Cepeda, Jaime Córdoba Triviño, Rodrigo Escobar Gil, Marco Gerardo Monroy Cabra, Álvaro Tafur Galvis, Clara Inés Vargas; 18 de mayo de 2006).

Corte Constitucional de Colombia. Sentencia C-454 de 2006 (M. P. Jaime Córdoba Triviño; 7 de junio de 2006).

Corte Interamericana de Derechos Humanos (CtIDH), Opinión Consultiva N. 11/90, Opinión Consultiva Nr. 18/03, 17 de septiembre de 2003.

David Sokol, Reduced Victim Participation: A Misstep by the Extraordinary Chambers in the Courts of Cambodia, 10 Washington University Global Studies Law Review, n. ${ }^{\circ}$ 1, 167-186 (2011). https://openscholarship.wustl.edu/ cgi/viewcontent.cgi?article $=1016 \&$ context $=$ law_globalstudies

David Taylor, Victim Participation in Transitional Justice Mechanisms: ¿Real Power or Empty Ritual? (Impunity Watch, 2014). http://www.vrwg.org/downloads/iwdiscussionpapervictimparticipation 1.pdf

Decreto 1069 de 2015. Por medio del cual se expide el Decreto Único Reglamentario del Sector Justicia y del Derecho. 26 de mayo de 2015. D. O. 49523.

Decreto 1166 de 2018. Por el cual se adiciona un Capítulo al Título 5 de la Parte 2 del Libro 2 del Decreto número 1069 de 2015, Por el cual se expide el Decreto Reglamentario único del Sector Justicia y del Derecho, y se reglamenta el Sistema Autónomo de Asesoría y Defensa que se ofrecerá respecto a los trámites y actuaciones previstas en la Ley 1820 de 2016, ante el Sistema Integral de Verdad, Justicia, Reparación y No Repetición (SIVJRNR). 22 de julio de 2018. D. O. 50651.

Departamento Nacional de Planeación, La Superación de la situación de vulnerabilidad causada por el desplazamiento forzado: Un gran reto de la política pública dirigida a las víctimas del conflicto armado (s. f.). https://pazvictimas.dnp.gov.co/Como-se-responde-a-los-efectos-del-conflicto/Paginas/lasuperaciondelasit uaciondevulnerabilidadcausadaporeldesplazamiento.aspx

Extraordinary Chambers In The Court Of Cambodia (ECCC), Decision on Civil Party Participation in Provisional Detention Appeals, Nuon Chea and others, (002/19-09-2007/ECCC-C11/53), Pre-Trial Chamber, 20 de marzo de 2008.

Extraordinary Chambers In The Court Of Cambodia (ECCC), Office of the Co-Investigating Judges, Case 002, Order on the Organization of Civil Party Representation under Rule 23ter of the Rules, Co-Investigating Judges, 2 de agosto de 2010.

Extraordinary Chambers In The Court Of Cambodia (ECCC), Sixth ECCC Pleanary session concludes (s. f.). https ://www.eccc.gov.kh/en/articles/sixth-eccc-plenary-session-concludes

Fédération Internationale Pour Les Droits Humains (FIDH), A new scheme for Civil Party representation before the ECCC: Victims to bear the hightest burden in implementing the need for an expeditious trial, 3 de marzo de 2010. http://www.fidh.org/A-new-schemefor-Civil-Party

Fédération Internationale Pour Les Droits Humains (FIDH), Cutting the Weakest Link. Budget Discussions and their Impact on Victims' Rights to Participate in the Proceedings (Position paper, $11^{\text {th }}$ session of the Assembly of States Parties to the Rome Statute, 2012).

Fédération Internationale Pour Les Droits Humains (FIDH), Enhancing Victims' Rights before the ICC. A view from situation countries on victims' rights at the International Criminal Court (2013). https://www.fidh.org/en/issues/international-justice/international-criminal-court-icc/14259-fidh-re port-enhancing-victims-rights-before-the-icc-a-view-from-situation

Fédération Internationale Pour Les Droits Humains (FIDH), Five Myths about Victim Participation in ICC Proceedings (2014). https://www.fidh.org/en/issues/international-justice/international-criminal-court-icc/16592-five-my ths-about-victim-participation-in-icc-proceedings

Fédération Internationale Pour Les Droits Humains (FIDH), Victims at the Center of Justice? From 1998 to 2018: Reflections on the Promises and the Reality of Victim Participation at the ICC (2018). https://www.fidh.org/IM $\mathrm{G} / \mathrm{pdf} /$ droitsdesvictimes730a_final.pdf 
Fédération Internationale Pour Les Droits Humains (FIDH), Victims' Rights Before the ECCC. A Mixed Record for Civil Parties (2012). https://www.fidh.org/en/region/asia/cambodia/eccc/Victims-Rights-before-the-ECCCA-12533

Fiscalía General de la Nación, Resolución 3998 de 2006. Por la cual se establecen directrices para el procedimiento de recepción de versión libre en los asuntos de competencia de la Unidad Nacional de Fiscalías para la Justicia y la Paz, en desarrollo de la Ley 975 de 2005 y sus Decretos Reglamentarios 4760 de 2005, 2898 y 3391 de 2006. 13 de diciembre de 2006. D. O. 46481.

Harry Hobbs, Victim Participation in International Criminal Proceedings: Problems and Potential Solutions in Implementing an Effective and Vital Component of Justice, 49 Texas International Law Journal, 1-33 (2014).

Helen Jarvis, "Justice for the Deceased.: Victims' Paerticipation in the Extraordinary Chambers in the courts of Cambodia, 8 Genocide Studies and Prevention: An International Journal, n. ${ }^{\circ} 2$, 19-27 (2014). https://doi.org/10.5038/1 911-9933.8.2.4

Helen Jarvis, Trials and Tribulations: The long quest for Justice for the Cambodian Genocide, en The Extraordinary Chambers in the Courts of Cambodia, 13-44 (Simon M. Meisenberg \& Ignaz Stegmiller eds., Springer, 2016). https://doi.org/10.1007/978-94-6265-105-0_2

Herbert Jäger, Makrokriminalität: Studien zur Kriminologie Kollektiver Gewalt (Suhrkamp Verlag, 1989).

Human Rights Watch (HRW), Who Will Stand for Us? Victims'Legal Representation at the ICC in the Ongwen Case and Beyond (2017). https://www.hrw.org/report/2017/08/29/who-will-stand-us/victims-legal-representation -icc-ongwen-case-and-beyond

I Kai Ambos, Treatise on International Criminal Law: Foundations and General Part (Oxford University Press, 2013). https://doi.org/10.1093/law/9780199657926.001.0001

Ian Edwards, An Ambiguous Participant: The Crime Victim and Criminal Justice Decision-Making, 44 British Journal of Criminology, n. ${ }^{\circ} 6,967-982$ (2004). https://doi.org/10.1093/bjc/azh050

Ignaz Stegmiller, Legal Developments of Civil Party Participation at the ECCC, en The Extraordinary Chambers in the Courts of Cambodia, 535-550 (Simon M. Meisenberg \& Ignaz Stegmiller eds., Springer, 2016). https://do i.org/10.1007/978-94-6265-105-0_20

Inder Brigid, Statement by the Women's Initiatives for Gender Justice on the Opening of the ICC Trial of Jean-Pierre Bemba Gombo (2010). http://iccwomen.org/documents/Bemba_Opening_Statement.pdf.pdf

International Criminal Court (ICC), $8^{\text {th }}$ Asamblea Plenaria, Resolution ICC-ASP/11/Res.7, 21 November 2012.

International Criminal Court (ICC), Decision on Common Legal Representation of Victims for the Purpose of Trial, Bemba, ICC-01/05-01/08-1005, Trial Chamber III, 10 de noviembre de 2010.

International Criminal Court (ICC), Judgment pursuant to Article 74 of the Statute, Lubanga, ICC-01/04-01/06-2842, Trial Chamber I, 14 de marzo de 2012.

International Criminal Court (ICC), Legal framework and experience to date on common legal representation, Annex 1 to Proposal for the Common Legal Representation of Victims (2011). https://www.icc-cpi.int/RelatedReco rds/CR2011_11851.PDF

International Criminal Court (ICC), Prosecutor v. Germain Katanga (Case No. ICC-01/04-01/07-1788-T), Trial Chamber II, Decision on the Modalities of Victim Participation at Trial, 22 de enero de 2010.

International Criminal Court (ICC), Rules of Procedure and Evidence (ICC-ASP/1/3 and Corr.1) (2002). https://w ww.icc-cpi.int/iccdocs/pids/legal-texts/rulesprocedureevidenceeng.pdf

International Criminal Court (ICC) \& Assembly of States Parties, Mandates of the Assembly of States Parties for the intersessional period, Annex I to Strengthening the International Criminal Court and the Assembly of States Parties, Res. ICC-ASP/14/20 (2015). https://asp.icc-cpi.int/iccdocs/asp_docs/Resolutions/ASP14/ICC-ASP -14-Res4-ENG.pdf\#page $=15$

JEP Colombia, Audiencia de régimen de condicionalidad. Caso Gaula Casanare. Agosto 30 de 2018. HD, YouTube (10 de septiembre de 2018), https://www.youtube.com/watch?v=ZKeyTjuj05k 
JEP Colombia, Audiencia de régimen de condicionalidad. Mondoñedo II. Noviembre 20 de 2018. HD, YouTube (3 de diciembre de 2018), https://www.youtube.com/watch?v=h_tddODdjso

JEP Colombia, Audiencia Pública para escuchar a familiares de los jóvenes de Soacha ejecutados extrajudicialmente, YouTube (17 de octubre de 2019), https://www.youtube.com/watch?v=or-eN1imsfE

Jurisdicción Especial para la Paz (JEP), Ante la JEP se han acreditado 1.276 víctimas de secuestro cometidos presuntamente por la extinta guerrilla de las Farc-EP, 14 de noviembre de 2019. https://www.jep.gov.co/Sala-de-Prensa/Paginas/Ante-la-JEP-se-han-acreditado-1.276-v\%C3\%ADctim as-de-secuestro-cometidos-presuntamente-por-la-extinta-guerrilla-de-las-Farc-EP.aspx

Jurisdicción Especial para la Paz (JEP), Comunicado 147 de 2019, La JEP comienza acreditación de víctimas en las zonas humanitarias de Juguamiandó y Curvaradó, Chocó, 10 de octubre de 2019. https://www.jep.gov.co/Sala-de-Prensa/Paginas/La-JEP-comienza-acreditaci\%C3\%B3n-de-v\%C3\%AD ctimas-en-las-zonas-humanitarias-de-Jiguamiand\%C3\%B3-y-Curvarad\%C3\%B3-Choc\%C3\%B3.aspx

Jurisdicción Especial para la Paz (JEP), Empezó el proceso de acreditación de víctimas dentro del Caso 05, 25 de septiembre de 2019. https://www.jep.gov.co/Sala-de-Prensa/Paginas/Empez\%C3\%B3-el-proceso-de-acreditac i\%C3\%B3n-de-v\%C3\%ADctimas-dentro-del-Caso-05.aspx

Jurisdicción Especial para la Paz (JEP), Presidencia, Resolución 001 de 2018, enero 15 de 2018.

Jurisdicción Especial para la Paz (JEP), Sala de Reconocimiento de Verdad, de Responsabilidad, y de Determinación de los Hechos y conductas (SRVR), Auto 080, 28 de mayo de 2019.

Jurisdicción Especial para la Paz (JEP), Sala de Reconocimiento de Verdad, de Responsabilidad, y de Determinación de los Hechos y conductas (SRVR), Auto No. 005, por el cual se avoca conocimiento del Caso No. 003 "Muertes ilegítimamente presentadas como bajas en combate por agentes del Estado", 17 de julio de 2018.

Jurisdicción Especial para la Paz (JEP), Sala de Reconocimiento de Verdad, de Responsabilidad, y de Determinación de los Hechos y conductas (SRVR), Auto No. 222, por medio del cual se adopta la prórroga del plazo para presentar informes ante la Sala de Reconocimiento de Verdad, de Responsabilidad de Determinación de los Hechos y Conductas por parte de organizaciones de víctimas, indígenas, negras, afrocolombianas, raizales, palenqueras, Rrom y de derechos humanos colombianas, 8 de octubre de 2019.

Jurisdicción Especial para la Paz (JEP), Sala de Reconocimiento de Verdad, de Responsabilidad, y de Determinación de los Hechos y conductas (SRVR), Auto SRVR Caso 003, Acreditación de víctimas de hechos relacionados con el Caso No. 003 de la SRVR, reconocimiento de la personería jurídica de sus representantes, y, traslado de las versiones voluntarias a las víctimas y sus representantes, 6 de febrero de 2019.

Jurisdicción Especial para la Paz (JEP), Sala de Reconocimiento de Verdad, de Responsabilidad, y de Determinación de los Hechos y conductas (SRVR), Caso No. 005 Situación territorial en la región del norte del Cauca, 8 de noviembre de 2018.

Jurisdicción Especial para la Paz (JEP), Sección de Apelación, SA-TP-SENIT 1 de 2019, 3 de abril de 2019.

Jurisdicción Especial para la Paz (JEP), Secretaría Ejecutiva, Respuesta 16 de agosto de 2019, derecho de petición radicado Orfeo 20191510254852.

Jurisdicción Especial para la Paz (JEP), Secretaría Ejecutiva, Respuesta de 27 de septiembre de 2019, derecho de petición radicado Orfeo 20191510433972.

Kai Ambos, Florian Huber, Rodrigo A. González-Fuente Rubilar \& John E. Zuluaga Taborda, Procedimiento de la Ley de Justicia y Paz (Ley 975 de 2005) y Derecho Penal Internacional. Estudio sobre la facultad de intervención complementaria de la Corte Penal Internacional a la luz del denominado proceso de "justicia y paz" en Colombia (Deutsche Gesellschaft für Technische Zusammenarbeit (GTZ) GmbH, 2010). http://www.corteidh.or.cr/tab las/26869.pdf

Ley 1592 de 2012. Por medio de la cual se introducen modificaciones a la Ley 975 de 2005 "por la cual se dictan disposiciones para la reincorporación de miembros de grupos armados organizados al margen de la ley, que contribuyan de manera efectiva a la consecución de la paz nacional y se dictan otras disposiciones para acuerdos humanitarios" y se dictan otras disposiciones. 3 de diciembre de 2012. D. O. 48.633. 
Ley 1922 de 2018. Por medio de la cual se adoptan unas reglas de procedimiento para la Jurisdicción Especial para la Paz. 18 de julio de 2018. D. O. 50658.

Ley 1957 de 2019. Ley Estatutaria de la Administración de Justicia en la Jurisdicción Especial para la Paz. 6 de junio de 2019. D. O. 50.976.

Luke Moffet, RealisingJustice for Victims before the International Criminal Court (International Crimes Database Brief 6,2014). http://www.internationalcrimesdatabase.org/upload/documents/20140916T170017-ICD\%20Brief \%20-\%20Moffett.pdf

Mahdev Mohan, The Paradox of Victim-Centrism: Victim Participation at the Khmer Rouge Tribunal, 9 International Criminal Law Review, n. ${ }^{\circ}$ 5, 733-775 (2009). https://doi.org/10.1163/156753609X12507729201318

Mark Osiel, Making sense of Mass Atrocity (Cambridge university Press, 2009). https://doi.org/10.1017/CBO978 0511596575

Matriz Comité Interinstitucional de Justicia y Paz, periodo marzo 2017

Michelle Staggs Kelsall, Mary Kristerie A. Baleva, Aviva Nababan, Vineath Chou, Rachel Guo, Caroline Ehlert, Sovannith Nget \& Savornt Pheak, Lessons Learned from the 'Duch' Trial: A Comprehensive Review of the First Case before The Extraordinary Chambers In The Courts OfCambodia (Asian International Justice Initiative's KRT Trial Monitoring Group, 2009). https://www.legal-tools.org/doc/727823/pdf

Miriam Forero, Estos son los municipios más afectados por el conflicto, ColombiaCheck, (28 de octubre de 2016). https ://colombiacheck.com/investigaciones/estos-son-los-municipios-mas-afectados-por-el-conflicto

Movimiento Nacional De Víctimas De Estado (Movice), Sin Justicia y sin paz. Verdad fragmentada, reparación ausente (2009). https://nuncamas.movimientodevictimas.org/index.php/producto/sin-justicia-y-sin-paz-verd ad-fragmentada-reparacion-ausente-balance-de-la-aplicacion-de-la-ley-de-justicia-y-paz/

Naciones Unidas, Estatuto de Roma de la Corte Penal Internacional, documento A/CONF.183/9 (1998). http://ww w.un.org/spanish/law/icc/statute/spanish/rome_statute(s).pdf

Nadien Kirchenbauer, Mychelle Balthazard, Latt Ky, Patrick Vinck, \& Phuong Pham, Victims' Participation Before the Extraordinary Chambers in The Courts Of Cambodia: Baseline Study Of The Cambodian Human Rights And Development Association's Civil Party Scheme For Case 002 (Phnom Penh: Harvard Humanitarian Initiative and Cambodian Human Rights and Development Association (ADHOC), 2013). http://www.cambodiatribunal. org/assets/pdf/reports/Victims-participation-before-ECCC-Baseline-Study-Jan-2013.pdf

OEA, Décimo cuarto informe trimestral del Secretario General al Consejo Permanente sobre la Misión de Apoyo al Proceso de Paz en Colombia (MAPP/OEA), 9 OEA/Ser.G, CP/DOC. 4486/10 CORR. 1 (2010). http://ww w.bivipas.unal.edu.co/handle/10720/337

Organización de las Naciones Unidas, Asamblea General, Informe del Relator Especial sobre la promoción de la verdad, la justicia, la reparación y las garantías de no repetición, Pablo de Greiff, ONU, (Doc. A/HRC/21/46), 12 de agosto de 2012.

Organización de las Naciones Unidas, Asamblea General, Oficina De Las Naciones Unidas Contra La Droga y el Delito, Principios y directrices de las Naciones Unidas sobre el acceso a la asistencia jurídica, E/CN.15/2012/ 1.14/Rev.1, noviembre de 2013.

Organización de las Naciones Unidas, Asamblea General, Principios y directrices básicos sobre el derecho de las víctimas de violaciones manifiestas de las normas internacionales de derechos humanos y de violaciones graves del derecho internacional humanitario a interponer recursos y obtener reparaciones. Resolución 60/147, 16 de diciembre de 2005.

Organización de las Naciones Unidas, Declaración sobre los principios fundamentales de justicia para las víctimas de delitos y abuso de poder, Resolución 40/34, 29 de noviembre de 1985.

Ralph Sprenkels, Restricted Access: Promises and Pitfalls of Victim Participation in Transitional Justice Mechanisms. A comparative Perspective (Impunity Watch, 2018). https://dspace.library.uu.nl/handle/1874/376280

REDRESS, Representing victims before the ICC: Recommendations on the Legal Representation System (2015). https:/ /redress.org/wp-content/uploads/2017/12/1504reprentingvictims.pdf 
Revista Semana, Casos de 8163 secuestrados y 1620 víctimas de la UP ya están en manos de la JEP (30 de mayo de 2018). https://www.semana.com/nacion/articulo/fiscalia-entrego-informes-a-la-jep-sobre-exterminio-de-la -union-patriotica-y-los-secuestros-de-las-farc/569344

Revista Semana, Los 100 municipios criticos (2013). https://especiales.semana.com/especiales/proyectovictimas/100 -municipios-criticos/index.html

Rudina Jasini \&Victoria Phan, Victim participation at the Extraordinary Chambers in the Courts of Cambodia: are retributive and restorative principles enhancing the prospect for justice?, 24 Cambridge Review of International Affairs, n. ${ }^{\circ}$ 3, 379-401 (2011). https://doi.org/10.1080/09557571.2011.617001

Sara Kendall \& Sarah Nouwen, Representational practices at the International Criminal Court: The gap between juridified and abstract victimhood, Law \& Contemporary Problems, 76, 235-262 (2013). https://doi.org/10.21 39/ssrn.2313094

Susana Sácouto, Victim Participation at the International Criminal Court and the Extraordinary Chambers in the Courts of Cambodia: A Feminist Project, 18 Michigan Journal of Gender \& Law, n. 2, 297-359 (2012). https:/ /repository.law.umich.edu/mjgl/vol18/iss2/2/

The KRT Trial Monitor Report, Prosecutor v Kaing Guek Eav, alias 'Duch' (2009). https://krttrialmonitor.files.wor dpress.com/2012/07/aiji_eccc_case1_no7_31may09_en.pdf

Unidad para la Atención y Reparación Integral a las Víctimas, Registro ünico de Víctimas (RUV), https://www.unid advictimas.gov.co/es/registro-unico-de-victimas-ruv/37394

VII Carolin Reese, Großverbrechen und kriminologische Konzepte: Versuch einer theoretischen Integration (LITit Verlag Münster, 2004).

\section{Notas}

[1] Conforme al Registro único de Víctimas (RUV), a 18 de agosto de 2019 se registra un total de 8.493 .100 víctimas del conflicto armado. Aun cuando la competencia temporal de la JEP solo tomará en cuenta los hechos victimizantes ocurridos hasta el 1 de diciembre de 2016, y en virtud de la competencia en ratione personae el universo de hechos victimizantes y víctimas podría ser acotado, se podría decir que los hechos que eventualmente investigará y juzgará la JEP involucran en principio a millones de víctimas. Ver: https://www.unidadvictimas.gov.co/es/registro-unico-de-victimas -ruv/37394. (visto por última vez el 18 de agosto de 2019)

[2] Los casos priorizados por la JEP hasta la fecha son: Caso 001 sobre Retenciones ilegales presuntamente cometidas por las FARC-EP entre 1993 y 2012; Caso 002 sobre la Situación en los municipios de Ricaurte, Tumaco y Barbacoas en el departamento de Nariño por los hechos presuntamente cometidos por miembros de las FARC-EP y de la Fuerza Pública entre 1990 y 2016; Caso 003 sobre Muertes ilegitimamente presentadas como bajas en combate por agentes del Estado; Caso 004 sobre la situación humanitaria en Urabá entre 1986 y 2016; Caso 005 sobre la situación territorial de la región del Norte del Cauca y sur del Valle del Cauca por los hechos cometidos presuntamente por miembros de las FARC-EP y la Fuerza Pública entre el 1 de enero de 1993 y con anterioridad al 1 de diciembre de 2016; Caso 006 sobre Victimización de miembros de la Unión Patriótica (UP por parte de agentes del Estado); Caso 007 sobre Reclutamiento y utilización de niñas y niños en el conflicto armado colombiano.

[3] El término "macrocriminalidad" fue usado originalmente por Jäger y definido como "die gravierenden und gefährlichen Großformen kollektiver Gewalt” [La formas graves y peligrosas de violencia colectiva (trad. Propia)]. A partir de esta definición de Jäger se tiene que la macrocriminalidad se caracteriza porque el delito sea resultado de una acción colectiva que implica la participación del Estado, de una parte de la sociedad en forma de una estructura organizativa, o de un aparato de poder organizado. Ver: Herbert Jäger, Makrokriminalität: Studien zur Kriminologie Kollektiver Gewalt, 11-12 (Suhrkamp Verlag, 1989).

[4] De los casos mencionados, hasta la fecha los Casos 001, 003, 006 y 007 tienen connotación nacional.

[5] La macrovictimización se refiere a un número indeterminado de víctimas que ha sufrido impactos y daños como consecuencia de una criminalidad en masa o una situación de violencia masiva. Este concepto se relaciona con la macrocriminalidad que caracteriza a los crímenes internacionales, en tanto su carácter masivo, generalizado, o sistemático trae como consecuencia un impacto que afecta a una pluralidad de víctimas más allá de los impactos de los delitos ordinarios. VII Carolin Reese, Großverbrechen und kriminologische Konzepte: Versuch einer theoretischen Integration, 292-295 (LITit Verlag Münster, 2004). Mark Osiel, Making sense of Mass Atrocity, 5-6 (Cambridge university Press, 2009). 
[6] Cabe aclarar que parte de las estrategias para abordar la masividad de crímenes cometidos en escenarios de derecho penal internacional y justicia transicional son los criterios de selección y priorización de casos, lo que significa que no se pueden abordar penalmente todos los crímenes cometidos. Sin embargo, este no es un mecanismo suficiente, en muchos contextos, para dar vía libre a la participación de víctimas en los procesos sin que esto signifique un colapso de los mecanismos de justicia. En este sentido, la participación colectiva es una solución evidente para afrontar estos retos, pero también se puede observar que tanto la CPI como la ECCC han modificado su postura inicial de apertura a la participación restringiendo también las modalidades y momentos de participación durante los procesos. Ver: International Criminal Court (ICC), Prosecutor v. Germain Katanga (Case No. ICC-01/04-01/07-1788-T), Trial Chamber II, Decision on the Modalities of Victim Participation at Trial, 22 de enero de 2010, par.92-93. Alain Werner \& Daniella Rudy, Civil party representation at the ECCC: Sounding the retreat in international criminal law, 8 Northwestern Journal of International Human Rights, n. ${ }^{\circ} 3$, 302-303 (2009); Fédération Internationale Pour Les Droits Humains (FIDH), A new scheme for Civil Party representation before the ECCC: Victims to bear the hightest burden in implementing the need for an expeditious trial, 3 de marzo de 2010.

[7] Cuando se habla de participación significativa y efectiva para las víctimas en procesos penales bien sea en Tribunales internacionales o en contextos de Justicia Transicional, se hace referencia a unas condiciones mínimas que se deben satisfacer dentro del paradigma de la "centralidad de las víctimas". Al respecto, Sehmi, afirma que hay dos condiciones básicas para que se pueda hablar de una participación significativa de las víctimas: i) Una comunicación consistente entre la Corte y las víctimas, ii) la implementación de un enfoque holístico de participación que enfatice la restauración de la dignidad de las víctimas. Anushka Sehmi, Now that we have no voice, what will happen to us?': Experiences of Victim Participation in the Kenyatta Case, 16, Journal of International Criminal Justice, 579 (2018). Sprenkels, sostiene que una participación significativa de las víctimas implica la posibilidad de incidencia y de toma de decisiones de las víctimas en los mecanismos de la Justicia Transicional. Ralph Sprenkels, Restricted Access: Promises and Pitfalls of Victim Participation in Transitional Justice Mechanisms. A comparative Perspective, 48 (Impunity Watch, 2018). Según el Relator Especial de la ONU para la promoción de la Verdad, Justicia, Reparación y No Repetición, la participación significativa de las víctimas implica que estas y sus familias estén involucradas en los procesos penales y se les provee la información necesaria para su participación. Organización de las Naciones Unidas, Asamblea General, Informe del Relator Especial sobre la promoción de la verdad, la justicia, la reparación y las garantías de no repetición, Pablo de Greiff, ONU, (Doc. A/ HRC/21/46), 12 de agosto de 2012, párr. 54. Para efectos de este artículo y basado en las fuentes mencionadas, se entenderá por participación efectiva de las víctimas en los procedimientos penales la posibilidad de que las víctimas estén informadas, tengan voz ante los tribunales, y sus intereses y preocupaciones sean tenidos en cuenta, a la par con un mínimo de agencia en la toma de decisiones que les afectan respecto a su participación procesal.

[8] Jurisdicción Especial para la Paz (JEP), Sección de Apelación, SA-TP-SENIT 1 de 2019, 3 de abril de 2019, parte resolutiva (Tercero).

[9] Jurisdicción Especial para la Paz (JEP), Secretaría Ejecutiva, Respuesta 16 de agosto de 2019, derecho de petición radicado Orfeo 20191510254852.

[10] El paradigma de centralidad de las mismas se evidencia en el mismo Acuerdo Final de Paz (AFP) entre Gobierno colombiano y FARC-EP, en tanto el punto 5 del Acuerdo por el cual se crea el SIVJRNR plantea que las víctimas están en el centro del Acuerdo. La participación de las víctimas, se establece en la "Declaración de principios de 7 de junio de 2014" documento que debe irradiar la implementación del punto 5 del AFP. Conforme a este principio, la discusión sobre la satisfacción de los derechos de las víctimas requiere necesariamente de la participación de las víctimas, por diferentes medios y en diferentes momentos y que la creación de los diferentes mecanismos del SIVJRNR debe garantizar sus derechos. En la implementación de la JEP es notable que la Ley Estatutaria de la Administración de Justicia en la JEP consagra de manera explícita tanto la centralidad de los derechos de las víctimas (artículo 13), como la participación efectiva de las víctimas según los estándares nacionales e internacionales (artículo 14).

[11] Antes de la creación de la CPI a través del Estatuto de Roma de 1998, las víctimas habían tenido una participación marginal en tribunales ad hoc de carácter internacional como lo fueron los tribunales de Nürember, Tokio y posteriormente de ExYugoslavia y Ruanda. La CPI no solo es el primer tribunal penal internacional de carácter permanente, sino el primer tribunal internacional en dar un rol mucho más importante a las víctimas. Este rol, está dado no solo por la posibilidad de participar en los procedimientos, sino también por la posibilidad de recibir reparaciones. Las ECCC son un tribunal híbrido o internacionalizado pues combina jueces, fiscales, representantes legales, normatividad y presupuesto tanto internacional como camboyano creado en 2003. Las ECCC otorgan a las víctimas la posibilidad de ser partes civiles dentro del proceso penal, convirtiéndose en un caso paradigmático de participación de víctimas, teniendo en cuenta que es la primera vez que se abre esta posibilidad en un tribunal internacionalizado. Ver, entre otros: I Kai Ambos, Treatise on International Criminal Law: Foundations and General Part, 167-171 (Oxford University Press, 2013). Brianne McGonigle Leyh, Procedural Justice? Victim participation in international criminal proceedings, 172-173 (Intersentia, 2011); Luke Moffet, Realising Justice for Victims before the International Criminal Court (International Crimes Database Brief 6, 2014). 
[12] David Taylor, Victim Participation in Transitional Justice Mechanisms: Real Power or Empty Ritual?, $22-27$ (Impunity Watch, 2014). Cabe aclarar que esta propuesta de tipología está a su vez basada en la propuesta de Ian Edwards: Ian Edwards, An Ambiguous Participant: The Crime Victim and Criminal Justice Decision-Making, 44 British Journal of Criminology, n. ${ }^{\circ}$ 6, 967-982 (2004).

[13] Al respecto de la garantía de contar con representación legal ver: Organización de las Naciones Unidas, Declaración sobre los principios fundamentales de justicia para las víctimas de delitos y abuso de poder, Resolución 40/34, 29 de noviembre de 1985; Organización de las Naciones Unidas, Asamblea General, Oficina De Las Naciones Unidas Contra La Droga y el Delito, Principios y directrices de las Naciones Unidas sobre el acceso a la asistencia jurídica, E/CN.15/2012/1.14/ Rev.1, noviembre de 2013, principio 4. Ver también: Corte Interamericana de Derechos Humanos (CtIDH), Opinión Consultiva N. 11/90, Opinión Consultiva Nr. 18/03, 17 de septiembre de 2003.

[14] Como se verá en la sección III del artículo, los escenarios de la CPI, las ECCC y los juicios de Justicia y Paz son ejemplos de implementación de participación colectiva de víctimas a través de representante legal común debido a la cantidad de víctimas que participan en los procesos penales y al tipo de crímenes que se investigan y juzgan.

[15] Así, por ejemplo, desde 2012 la Asamblea de Estados, parte del Estatuto de Roma, se inclinó por un enfoque de participación colectiva y promovió que se hicieran las enmiendas de marco legal necesarias para implementar un enfoque de participación de víctimas predominantemente colectivo. Ver: International Criminal Court (ICC), 8th Asamblea Plenaria, Resolution ICC-ASP/11/Res.7, sección 5. Por su parte, ante las ECCC, debido al gran número de víctimas que fueron reconocidas como parte civil en el proceso a partir del Caso 002, la Corte decidió que debían agruparse y actuar a través de representante legal común. Ver: Extraordinary Chambers In The Court Of Cambodia (ECCC), Office of the Co-Investigating Judges, Case 002, Order on the Organization of Civil Party Representation under Rule 23ter of the Rules, Co-Investigating Judges, 2 de agosto de 2010.

[16] Es notable que los costos del sistema de representación gratuita de víctimas de la CPI incrementaron en 2012 aproximadamente un $150 \%$ más del presupuesto, lo que significa que se ha incrementado también la actividad judicial y el número de víctimas participantes. A pesar de que los mecanismos de participación colectiva son la regla en los procedimientos ante la CPI, existen tensiones respecto del Sistema de representación legal gratuito precisamente en razón de las limitaciones presupuestales de la CPI. Ver: Fédération Internationale Pour Les Droits Humains (FIDH), Cutting the Weakest Link. Budget Discussions and their Impact on Victims' Rights to Participate in the Proceedings, 11-12 (Position paper, $11^{\text {th }}$ session of the Assembly of States Parties to the Rome Statute, 2012).

[17] Ante la CPI, dadas las dificultades logísticas y los costos que implicaría traer a todas las víctimas desde sus países de residencia hasta la sede de la Corte en La Haya, los mecanismos de participación indirecta y colectiva mediada por representantes legales y otros intermediarios indudablemente han facilitado que la participación de víctimas tenga lugar en este escenario. Del mismo modo, en escenarios de justicia transicional a nivel en Colombia, se debe tener en cuenta que la mayoría de víctimas residen en regiones rurales y apartadas, por lo que además de la descentralización de algunas diligencias judiciales de las grandes urbes, especialmente Bogotá, la alternativa de la representación legal colectiva ahorra esfuerzos y costos para permitir que un número amplio de víctimas de zonas apartadas puedan participar. Al respecto de la victimización en municipios y zonas rurales en Colombia ver: Miriam Forero, Estos son los municipios más afectados por el conflicto, ColombiaCheck, (28 de octubre de 2016).; Ver también: Revista Semana, Los 100 municipios críticos (2013).

[18] David Taylor, op. cit., 26.

[19] Brianne McGonigle Leyh, op. cit., 406.

[20] Fédération Internationale Pour Les Droits Humains (FIDH), Enhancing Victims' Rights before the ICC. A view from situation countries on victims' rights at the International Criminal Court, 23 (2013).

[21] Acto Legislativo 01 de 2017, Por medio de la cual se crea un título de disposiciones transitorias de la constitución para la terminación del conflicto armado y la construcción de una paz estable y duradera y se dictan otras disposiciones, 4 de abril de 2017, artículo Transitorio 12; Ley 1922 de 2018, Por medio de la cual se adoptan unas reglas de procedimiento para la Jurisdicción Especial para la Paz, artículos 12, 13, 14 y 35.

[22] Ley 1922 de 2018 (Ley de Procedimiento JEP), artículo 1 (lit. b), 27.

[23] Uno de los escenarios más importantes en los que se pretende aplicar este procedimiento es en la construcción de la verdad. Específicamente, en la audiencia pública de reconocimiento de verdad y responsabilidad ante la SRVR. En esta audiencia se abre la posibilidad de que las víctimas asistan y puedan expresar sus observaciones respecto a la verdad otorgada por comparecientes, así como a los proyectos restaurativos que estos propongan. Adicionalmente, la normatividad abre la posibilidad a que se aplique la construcción dialógica de la verdad en todas las fases del procedimiento. Ver: Ley 1922 de 2018 (Ley de Procedimiento JEP) art. 27C. Asimismo, en casos de reconocimiento tardío de responsabilidad, en el marco de procedimientos con carácter adversarial, se prevé la posibilidad de que tenga lugar la "Audiencia Restaurativa" con participación de víctimas y acusados. Ley 1922 de 2018 (Ley de Procedimiento JEP), art. 44

[24] Ley 1922 de 2018 (Ley de Procedimiento JEP), artículo 1, C (Enfoques diferenciales y diversidad territorial). 
[25] Así, por ejemplo, algunas mujeres víctimas de violencia sexual son al mismo tiempo indígenas o afrocolombianas, lo que significa que al mismo tiempo debe recaer sobre ellas el enfoque de género y el enfoque étnico. En ese sentido, por ejemplo, la Ley Estatutaria de la Administración de Justicia en la JEP (LEAJ-JEP) establece en el art. 16 que las víctimas de violencia sexual pertenecientes a pueblos indígenas deben contar con un enfoque étnico además de las consideraciones especiales que se deben aplicar para todas las víctimas de violencia sexual en el marco de la JEP.

[26] Jurisdicción Especial para la Paz (JEP), Secretaría Ejecutiva, Respuesta 16 de agosto de 2019, derecho de petición radicado Orfeo 20191510254852; Jurisdicción Especial para la Paz (JEP), Secretaría Ejecutiva, Respuesta de 27 de septiembre de 2019, derecho de petición radicado Orfeo 20191510433972.

[27] Ley 1957 de 2019, Ley Estatutaria de la Administración de Justicia-JEP (LEAJ-JEP), 6 de junio de 2019, art. 12.

[28] Ley 1922 de 2018 (Ley de Procedimiento JEP), art. 9

[29] Organización de las Naciones Unidas, Asamblea General, Principios y directrices básicos sobre el derecho de las víctimas de violaciones manifiestas de las normas internacionales de derechos humanos y de violaciones graves del derecho internacional humanitario a interponer recursos y obtener reparaciones. Resolución 60/147, 16 de diciembre de 2005 , párrafo 8.

[30] Corte Constitucional de Colombia. Sentencia C-370 de 2006 (M. Ps. Manuel José Cepeda, Jaime Córdoba Triviño, Rodrigo Escobar Gil, Marco Gerardo Monroy Cabra, Álvaro Tafur Galvis, Clara Inés Vargas; 18 de mayo de 2006); Sentencia C-080 de 2018, parág. 4.1.11. (M. P. Antonio José Lizarazo, 15 de agosto de 2018).

[31] Íd.

[32] Jurisdicción Especial para la Paz (JEP), Sala de Reconocimiento de Verdad, de Responsabilidad, y de Determinación de los Hechos y conductas (SRVR), Auto SRVR Caso 003, Acreditación de víctimas de hechos relacionados con el Caso No. 003 de la SRVR, reconocimiento de la personería jurídica de sus representantes, y, traslado de las versiones voluntarias a las víctimas y sus representantes, 6 de febrero de 2019, parágs. 12-24.

[33] Ley 1922 de 2018 (Ley de Procedimiento JEP), artículo 4.

[34] Respecto a los recursos con que cuentan las víctimas, el art. 15 lit. b) de la LEAJ-JEP, se refiere al derecho que tienen las víctimas a interponer recursos contra sentencias. Esta norma debe interpretarse en armonía con el la Ley 1922 de 2018 (LP-JEP) que en sus artículos 12 a 14 establece que los intervinientes especiales pueden interponer recurso de reposición contra cualquier resolución que profieran las Salas y Secciones de la JEP, cuando esta decisión les afecte, o que pueden apelar las decisiones enunciadas en el artículo 13 cuando esta decisión le fuera desfavorable. Asimismo, las víctimas pueden interponer recurso de queja cuando sea negado el recurso de apelación (LP-JEP, art. 16). El art. 48 LEAJJEP reafirma las posibilidades de las víctimas en ese sentido, al establecer que las decisiones sobre renuncia a la persecución penal emitidas por la Sala de Definición de Situaciones Jurídicas de la JEP (SDSJ) pueden ser objeto de recursos no solo por el destinatario de la resolución, sino por las víctimas con interés directo y legítimo o sus representantes.

[35] Sentencia C-080 de 2018.

[36] Jurisdicción Especial para la Paz (JEP), Sección de Apelación, SA-TP-SENIT 1 de 2019, 3 de abril de 2019, parág. 214, 215.

[37] Ley 1922 de 2018 (Ley de Procedimiento JEP), art 27 D, n. ${ }^{\circ}$ 1. Si bien el plazo para presentación de informes de organizaciones de víctimas de derechos humanos inicialmente sería hasta marzo de 2020, mediante Auto No. 222 de 8 de octubre de 2019, la Sala de Reconocimiento de Verdad y Responsabilidad prorrogó este plazo hasta el 15 de marzo de 2021. Jurisdicción Especial para la Paz (JEP), Sala de Reconocimiento de Verdad, de Responsabilidad, y de Determinación de los Hechos y conductas (SRVR), Auto No. 222, por medio del cual se adopta la prórroga del plazo para presentar informes ante la Sala de Reconocimiento de Verdad, de Responsabilidad de Determinación de los Hechos y Conductas por parte de organizaciones de víctimas, indígenas, negras, afrocolombianas, raizales, palenqueras, Rrom y de derechos humanos colombianas, 8 de octubre de 2019.

[38] En ese sentido, bien puede tratarse de apoderado de confianza o de representante legal designado por la organización de víctimas que viene actuando en interés de la víctima, por ejemplo, a través de la presentación de informes o que ya venía actuando en su nombre en procesos en jurisdicción ordinaria, y que, con su anuencia, continúa representándola ante la JEP. Ver: Ley 1922 de 2018 (Ley de Procedimiento JEP), Artículo 2

[39] Así por ejemplo en algunas audiencias de condicionalidad que han tenido lugar en ante la Sala de Definición de Situaciones Jurídicas (SDSJ), se ha observado que, además de las intervenciones de los representantes legales, las víctimas han tenido oportunidad de expresar por sí mismas sus opiniones y observaciones. Ver: JEP Colombia, Audiencia de régimen de condicionalidad. Caso Gaula Casanare. Agosto 30 de 2018. HD, YouTube (10 de septiembre de 2018); JEP Colombia, Audiencia de régimen de condicionalidad. Mondoñedo II. Noviembre 20 de 2018. HD, YouTube (3 de diciembre de 2018).

[40] LEAJ-JEP, arts. 15, 112 núm. 14, 115. Ver Supra nota 25.

[41] El SAAD es administrado por la Secretaría Ejecutiva de la JEP, y su objetivo es asegurar el ejercicio del derecho de defensa de las personas comparecientes ante la JEP, así como el derecho de asesoría jurídica de las víctimas cuando no cuentan con los recursos económicos suficientes. Ver: LEAJ-JEP, Art. 115; Decreto 1166 de 2018 
[42] Hasta la fecha, el SAAD cuenta con 3 abogados contratados para prestar servicios de asesoría legal gratuita. Adicionalmente, mediante Acuerdo de Cooperación (Acuerdo No. 171 de 2019) entre la JEP con el Programa de las Naciones Unidas para el Desarrollo (PNUD), el SAAD cuenta con recursos para financiar la contratación de los servicios de organizaciones que históricamente han asumido la representación común de las víctimas en Colombia, a fin de que atiendan las necesidades de participación en territorios diferentes a Bogotá. Jurisdicción Especial para la Paz (JEP), Secretaría Ejecutiva, Respuesta 16 de agosto de 2019, derecho de petición radicado Orfeo 20191510254852 y Respuesta de 27 de septiembre de 2019, derecho de petición radicado Orfeo 20191510433972.

[43] Así, por ejemplo, en junio de 2018, el SAAD publicó una invitación para organizaciones afrocolombianas, raizales, palenqueras y Rrom con experiencia en asesoría y representación judicial a víctimas, para conformar un banco de elegibles en los casos que se requiera servicios de representación judicial bajo este enfoque étnico. Adicionalmente, según la respuesta de la Secretaría Ejecutiva a uno de los derechos de petición presentados, se han vinculado a otras organizaciones con experiencia en representación jurídica de víctimas tales como PCN Hileros, CRIC, ONIC, y Humanas, para representar a víctimas acreditadas en los casos 001, 002, 003, 004, y 005. Jurisdicción Especial para la Paz (JEP), Secretaría Ejecutiva, Respuesta de 27 de septiembre de 2019, derecho de petición radicado Orfeo 20191510433972.

[44] Jurisdicción Especial para la Paz (JEP), Secretaría Ejecutiva, Respuesta 16 de agosto de 2019, derecho de petición radicado Orfeo 20191510254852.

[45] Jurisdicción Especial para la Paz (JEP), Comunicado 147 de 2019, La JEP comienza acreditación de víctimas en las zonas humanitarias de Juguamiandó y Curvaradó, Chocó, 10 de octubre de 2019.

[46] Sentencia C-080 de 2018, parág. 4.1.11.

[47] Íd., análisis del artículo 14 LEAJ-JEP

[48] Íd.

[49] Jurisdicción Especial para la Paz (JEP), Sección de Apelación, SA-TP-SENIT 1 de 2019, 3 de abril de 2019, parág. 109.

[50] La JEP tendrá un plazo máximo de funcionamiento de 15 años, prorrogables por 5 años más, a partir del 15 de enero de 2018 cuando entró en funcionamiento. Acto Legislativo No. 1 de 2017, artículo 1; Jurisdicción Especial para la Paz (JEP), Presidencia, Resolución 001 de 2018, enero 15 de 2018.

[51] Jurisdicción Especial para la Paz (JEP), Sección de Apelación, SA-TP-SENIT 1 de 2019, 3 de abril de 2019, parág. 111.

[52] Ley de Procedimiento JEP, art. 2, párrafos segundo y tercero.

[53] Íd., art. 10.

[54] Jurisdicción Especial para la Paz (JEP), Secretaría Ejecutiva, Respuesta 16 de agosto de 2019, derecho de petición radicado Orfeo 20191510254852.

[55] Jurisdicción Especial para la Paz (JEP), Secretaría Ejecutiva, Respuesta de 27 de septiembre de 2019, derecho de petición radicado Orfeo 20191510433972.

[56] Jurisdicción Especial para la Paz (JEP), Sección de Apelación, SA-TP-SENIT 1 de 2019, 3 de abril de 2019, parte resolutiva (Tercero).

[57] Íd., parág. 112.

[58] Íd., Parágs. 115-116.

[59] Respuesta 16 de agosto de 2019, derecho de petición ante la Secretaría Ejecutiva de la JEP, radicado Orfeo 20191510254852.

[60] Ver entre otros: Charles P. Trumbull IV, The Victims of Victim Participation in International Criminal Proceedings, 29 Michigan Journal of International Law, n. ${ }^{\circ} 4,811-819$ (2008); Harry Hobbs, Victim Participation in International Criminal Proceedings: Problems and Potential Solutions in Implementing an Effective and Vital Component of Justice, 49 Texas International Law Journal, 26-27 (2014); Sara Kendall \& Sarah Nouwen, Representational practices at the International Criminal Court: The gap between juridified and abstract victimhood, Law \& Contemporary Problems, 76, 248-251 (2013); Mahdev Mohan, The Paradox of Victim-Centrism: Victim Participation at the Khmer Rouge Tribunal, 9 International Criminal Law Review, n. ${ }^{\circ}$ 5, 733-775 (2009); David Taylor, op. cit., 9-11.

[61] Christine Van den Wyngaert Hon, Victims Before International Criminal Courts: Some Views and Concerns of an ICC Trial Judge, 44 Case Western Reserve Journal of International Law, n. 1 1, 489 (2011).

[62] Íd.

[63] En ese sentido ha sido notable la defensa de la participación de víctimas en tribunales internacionales o internacionalizados de organizaciones como la Federación Internacional para los Derechos Humanos (FIDH), Human Rights Watch (HRW), Redress, y Asian International Justice Initiative 's KRT Trial Monitoring Group.

[64] Ver, por ejemplo: Fédération Internationale Pour Les Droits Humains (FIDH), Five Myths about Victim Participation in ICC Proceedings, 19-22 (2014); Fédération Internationale Pour Les Droits Humains (FIDH), Victims at the Center of Justice? From 1998 to 2018: Reflections on the Promises and the Reality of Victim Participation at the ICC, 81-87 (2018).

[65] La regla 93 de las Reglas de Procedimiento y Evidencia de la CPI (RPE-CPI) enfatiza que las Salas de la CPI pueden solicitar las observaciones de las víctimas o sus representantes legales sobre cualquier cuestión. Es decir, si bien la 
normatividad establece de manera genérica la posibilidad de que las víctimas sean escuchadas, la decisión de los momentos de participación está a discreción de los jueces de la CPI.

[66] El Estatuto de Roma está nutrido de rasgos tanto del derecho continental como del derecho anglosajón, y esto se refleja en la posibilidad de víctimas participantes en los procedimientos. De hecho, la CPI es considerada un hito por sus rasgos restaurativos con respecto a las víctimas. Sin embargo, la tendencia acusatoria en los procedimientos es predominante y por ende las víctimas no tienen status de "partes" dentro de los procedimientos. Ver: Alexa Koenig, Eric Stover, Stephen Smith \& Mychelle Balthazard, The Victims Court: A Study of 622 Victim Participants at the International Criminal Court, 18-19 (Human Rights Center, University of California, 2015).

[67] Sobre la participación excepcional de víctimas como testigos ver: Brianne McGonigle Leyh, op. cit., 321-325.

[68] Alexa Koenig, Eric Stover, Stephen Smith \& Mychelle Balthazard, op. cit., 25.

[69] Human Rights Watch (HRW), Who Will Stand for Us? Victims'Legal Representation at the ICC in the Ongwen Case and Beyond, 9 (2017).

[70] International Criminal Court (ICC), Judgment pursuant to Article 74 of the Statute, Lubanga, ICC-01/04-01/06-2842, Trial Chamber I, 14 de marzo de 2012, párrs.15, 20.

[71] REDRESS, Representing victims before the ICC: Recommendations on the Legal Representation System, 8 (2015); Binxin Zhang, Recognizing the Limits of Victims Participation: A Comparative Examination of the Victim Participation Schemes at the ECCC and the ICC, en The Extraordinary Chambers in the Courts of Cambodia, 527-528 (Simon M. Meisenberg \& Ignaz Stegmiller eds., Springer, 2016); Human Rights Watch (HRW), Who Will Stand for Us?, op. cit., 15-21(2017)

[72] International Criminal Court (ICC), Legal framework and experience to date on common legal representation, Annex 1 to Proposal for the Common Legal Representation of Victims (2011). Respecto a las limitaciones presupuestales ver: International Criminal Court (ICC) \& Assembly of States Parties, Mandates of the Assembly of States Parties for the intersessional period, Annex I to Strengthening the International Criminal Court and the Assembly of States Parties, Res. ICC-ASP/14/20 (2015), parágs. 6 y 8).

[73] Ver: Binxin Zhang, op. cit., 528; Fédération Internationale Pour Les Droits Humains (FIDH), Victims at the center of Justice, op. cit., 49.

[74] Alexa Koenig, Eric Stover, Stephen Smith \& Mychelle Balthazard, op. cit., 72.

[75] Fédération Internationale Pour Les Droits Humains (FIDH), Enhancing Victims' Rights before the ICC, op. cit., 22 (2013).

[76] Fédération Internationale Pour Les Droits Humains (FIDH), Victims at the center of Justice, op. cit., 49.

[77] REDRESS, op. cit., 11.

[78] Alexa Koenig, Eric Stover, Stephen Smith \& Mychelle Balthazard, op. cit., 22.

[79] REDRESS, op. cit., 19.

[80] En las conclusiones del estudio realizado en 2015 por The Berkeley Law School, se indica que la mayoría de víctimas participantes querían más interacción con el personal de la CPI o con sus representantes legales, pues muy pocas personas pudieron tener más de tres encuentros con estos. Alexa Koenig, Eric Stover, Stephen Smith \& Mychelle Balthazard, $o p$. cit., 35, 43, 72 .

[81] Así, por ejemplo, en el caso Bemba, más de 5000 víctimas participantes eran representadas por solo dos apoderados. Ver: REDRESS, op. cit., 19-20.

[82] Anushka Sehmi, op. cit., 580-581.

[83] Fédération Internationale Pour Les Droits Humains (FIDH), Five myths about victim participation, 24-25.

[84] Íd.

[85] En este caso, por ejemplo, los representantes legales provistos por la CPI contaron con presupuesto para contratar asistentes en campo multilingües, cualificados legalmente e informados de las políticas étnicas de Kenya. Adicionalmente, resalta que los encuentros entre el equipo de la CPI y las víctimas iniciaban con una oración como parte de las costumbres culturales. Anushka Sehmi, op. cit., 582

[86] RPE - CPI, regla 90 (4)

[87] International Criminal Court (ICC), Decision on Common Legal Representation of Victims for the Purpose of Trial, Bemba, ICC-01/05-01/08-1005, Trial Chamber III, 10 de noviembre de 2010, parág. 18-20.

[88] Inder Brigid, Statement by the Women's Initiatives for Gender Justice on the Opening of the ICC Trial ofJean-Pierre Bemba Gombo (2010).

[89] Fédération Internationale Pour Les Droits Humains (FIDH), Victims at the center of Justice, op. cit., 49.

[90] Fédération Internationale Pour Les Droits Humains (FIDH), Enhancing Victims' Rights Before the ICC, op. cit., 18.

[91] Las partes civiles deben actuar siempre a través de sus representantes legales, como se estipula en la regla 23ter de las Reglas Internas. Se exceptúa la posibilidad que tienen los jueces coinvestigadores de entrevistar a las víctimas directamente conforme la Regla 59 de las Reglas Internas (RI-ECCC). 
[92] Sin embargo, la redacción de las Reglas Internas de las ECCC establece que la actuación de la parte civil debe apoyar el trabajo de la Fiscalía, lo cual podría interpretarse en el sentido de que las partes civiles no tienen derecho a iniciar una investigación o exigir a la fiscalía que investigue a un particular presunto responsable. Ver: RI-ECCC, regla 23 (Ver: Extraordinary Chambers In The Court Of Cambodia (ECCC), Decision on Civil Party Participation in Provisional Detention Appeals, Nuon Chea and others, (002/19-09-2007/ECCC-C11/53), Pre-Trial Chamber, 20 de marzo de 2008, parág. 36. Sumado a ello, a través de las enmiendas a las Reglas Internas y a diferentes desarrollos jurisprudenciales, los derechos de las partes civiles se han ido restringiendo, a tal punto que algunos críticos consideran que se está contrariando el propósito de promoción de la reconciliación de las ECCC. Ver, por ejemplo: David Sokol, Reduced Victim Participation: A Misstep by the Extraordinary Chambers in the Courts of Cambodia, 10 Washington University Global Studies Law Review, n. ${ }^{\circ}$ 1, 185-186 (2011).

[93] Inicialmente, solo el artículo 36 de la Ley de las ECCC contemplaba el derecho de las víctimas para apelar ante la Cámara de la Corte Suprema, pero fue hasta el desarrollo de las Reglas Internas en 2007 que se reguló la participación de las víctimas como partes civiles. Así, por ejemplo, fue creada la Sección de apoyo a las víctimas, pero solo entró en funcionamiento hasta 2010 porque no tenía signado presupuesto. Ver: Brianne McGonigle Leyh, op. cit., 217; Helen Jarvis, "Justice for the Deceased": Victims' Paerticipation in the Extraordinary Chambers in the courts of Cambodia, 8 Genocide Studies and Prevention: An International Journal, n. ${ }^{\circ}$ 2, $22-23$ (2014); Helen Jarvis, Trials and Tribulations: The long quest for Justice for the Cambodian Genocide, en The Extraordinary Chambers in the Courts of Cambodia, 31 (Simon M. Meisenberg \& Ignaz Stegmiller eds., Springer, 2016).

[94] Helen Jarvis, "Justice for the Deceased", op. cit., 23; Brianne McGonigle Leyh, op. cit., 219.

[95] Fédération Internationale Pour Les Droits Humains (FIDH), Victims' Rights Before the ECCC. A Mixed Record for Civil Parties, 34 (2012). Sobre las actividades de extensión y consulta con las víctimas ver: Nadien Kirchenbauer, Mychelle Balthazard, Latt Ky, Patrick Vinck, \& Phuong Pham, Victims' Participation Before the Extraordinary Chambers in The Courts Of Cambodia: Baseline Study Of The Cambodian Human Rights And Development Association's Civil Party Scheme For Case 002, 7-9 (Phnom Penh: Harvard Humanitarian Initiative and Cambodian Human Rights and Development Association [ADHOC], 2013).

[96] Binxin Zhang, op. cit., 523.

[97] Rudina Jasini \&Victoria Phan, Victim participation at the Extraordinary Chambers in the Courts of Cambodia: are retributive and restorative principles enhancing the prospect for justice?, 24 Cambridge Review of International Affairs, $\mathrm{n}$. ○3, 379-401 (2011).

[98] Ver: The KRT Trial Monitor Report, Prosecutor v Kaing Guek Eav, alias 'Duch' (2009).

[99] Cabe anotar que el Reglamento Interno de las ECCC ha sido enmendado nueve veces hasta el momento, y uno de los aspectos que ha sido objeto de más modificaciones es el concerniente a la participación de víctimas, como se evidencia en las reglas 12, 12bis, 12ter, 23, 23bis, 23ter, 23quater, y 23quinquies.

[100] RI- ECCC, regla 12ter.

[101] RI - ECCC, regla 12ter.

[102] Extraordinary Chambers In The Court Of Cambodia (ECCC), Sixth ECCC Pleanary session concludes (s. f.).

[103] RI-ECCC, reglas 12 ter. (1) (4), 34 (3). Ver también: Susana Sácouto, Victim Participation at the International Criminal Court and the Extraordinary Chambers in the Courts of Cambodia: A Feminist Project, 18 Michigan Journal of Gender \& Law, n. ${ }^{\circ}$ 2, 297-359 (2012).

[104] Ignaz Stegmiller, Legal Developments of Civil Party Participation at the ECCC, en The Extraordinary Chambers in the Courts of Cambodia, 524 (Simon M. Meisenberg \& Ignaz Stegmiller eds., Springer, 2016); Mahdev Mohan, op. cit.

[105] Binxin Zhang, op. cit., 524 .

[106] Michelle Staggs Kelsall, Mary Kristerie A. Baleva, Aviva Nababan, Vineath Chou, Rachel Guo, Caroline Ehlert, Sovannith Nget \& Savornt Pheak, Lessons Learned from the Duch's Trial: A Comprehensive Review of the First Case Before the ECCC, 31 (Asian International Justice Initiative\#s KRT Trial Monitoring Group, Phnom Penh, 2009)

[107] De esta manera, se puede observar que todos los juicios han sido transmitidos vía streaming y los videos se pueden acceder a través de la página web oficial de las ECCC. Ver: https://www.eccc.gov.kh/en/video/trial-video

[108] El procedimiento contempla una fase administrativa y una fase judicial. En la fase administrativa el Gobierno colombiano elaboró la lista de los miembros o postulados de grupos armados que se desmovilizarían y por ende accederían a los beneficios de la Ley de Justicia y Paz. La fase Judicial está a cargo de la Unidad Nacional de Fiscalía para la Justicia y la Paz y de los Tribunales de Justicia y paz. Estos entes inician la investigación y juzgamiento de los postulados de la lista que ha elaborado el Gobierno. Ver: Decreto 1069 de 2015, arts. 2.2.5.1.2.1.y ss.

[109] Corte Constitucional de Colombia. Sentencia C-228 de 2002 (M. Ps. Manuel José Cepeda Espinosa, Eduardo Montealegre Lynett; 3 de abril de 2002); Sentencia C-454 de 2006 (M. P. Jaime Córdoba Triviño; 7 de junio de 2006).

[110] Ley 1592 de 2012, art. 4 por el cual se modifica el artículo 6 de la Ley 975 de 2005.

[111] Íd., art. 3 por el cual se crea el artículo $5^{a}$ en la Ley 975 de 2005.

[112] Ley 975 de 2005, art 38. 
[113] El proceso penal especial de Justicia y Paz comienza con la diligencia de la versión libre. Esta diligencia consiste una en versión que rinden los desmovilizados ante la FGN sobre las circunstancias de tiempo, modo y lugar de los hechos delictivos en los que han participado (Ley 975 de 2005, art. 17).

[114] Resolución 3998 de 2006, Fiscalía General de la Nación, Art. 6

[115] Kai Ambos, Florian Huber, Rodrigo A. González-Fuente Rubilar \& John E. Zuluaga Taborda, Procedimiento de la Ley de Justicia y Paz (Ley 975 de 2005) y Derecho Penal Internacional. Estudio sobre la facultad de intervención complementaria de la Corte Penal Internacional a la luz del denominado proceso de “justicia y paz" en Colombia, parág. 281 (Deutsche Gesellschaft für Technische Zusammenarbeit (GTZ) GmbH, 2010).

[116] Íd., parágs. 289, 305, 306.

[117] Cifras del Comité Interinstitucional de Justicia y Paz, citadas por Kai Ambos, Íd., parág. 78.

[118] Íd., parág. 97 (2010)

[119] Matriz Comité Interinstitucional de Justicia y Paz, periodo marzo 2017, p. 32

[120] Contraloría General de la República, Análisis sobre los resultados y costos de la Ley de Justicia y Paz, 13 (2017).

[121] Movimiento Nacional De Víctimas De Estado (Movice), Sin Justicia y sin paz. Verdad fragmentada, reparación ausente, 56-61 (2009).

[122] Kai Ambos, Florian Huber, Rodrigo A. González-Fuente Rubilar \& John E. Zuluaga Taborda, op. cit., parágs. 97, 98, 289, 306.

[123] Andreas Forer, La participación de las víctimas en el marco de un proceso de justicia transicional - el caso colombiano en la Ley de Justicia y Paz, en Participación de las víctimas en la Ley de Justicia y Paz y Corte Penal Internacional, 11-56, 48-49 (Claudia López Díaz Comp., Giz, 2011).

[124] Contraloría General de la República, op. cit., 14. Cabe aclarar que, en las transmisiones en directo, si bien las víctimas están en un lugar diferente a donde se lleva a cabo la versión libre, en teoría, las víctimas pueden formular preguntas o pedir aclaraciones, ampliaciones o rectificaciones a través de un funcionario que disponga el Fiscal Delegado del caso.

[125] Andreas Forer, op. cit., 45- 46.

[126] OEA, Décimo cuarto informe trimestral del Secretario General al Consejo Permanente sobre la Misión de Apoyo al Proceso de Paz en Colombia (MAPP/OEA), 9 OEA/Ser.G, CP/DOC. 4486/10 CORR. 1 (2010).

[127] JEP, Ante la JEP se han acreditado 1276 víctimas de secuestro cometidos presuntamente por la extinta guerrilla de las Farc-EP, 14 de noviembre de 2019.

[128] Jurisdicción Especial para la Paz (JEP), Comunicado 147 de 2019, La JEP comienza acreditación de víctimas en las zonas humanitarias de Juguamiandó y Curvaradó, Chocó, 10 de octubre de 2019.

[129] Jurisdicción Especial para la Paz (JEP), Empezó el proceso de acreditación de víctimas dentro del Caso 05, 25 de septiembre de 2019.

[130] Tan solo para el caso 001 se han identificado 8163 víctimas, para el caso 003 hay alrededor de 1257 víctimas por hechos ocurridos entre 2006 y 2008, y en el Caso territorial 005 se han identificado en los municipios priorizados respecto al desplazamiento forzado alrededor de 376.873 víctimas, esto sin contar los otros hechos victimizantes que se estudian dentro de este caso. Ver: Informe No. 2 de la Fiscalía General de la Nación, "Retención ilegal de personas por parte de las Farc-EP, citado por Revista Semana, Casos de 8163 secuestrados y 1620 víctimas de la UP ya están en manos de la JEP (30 de mayo de 2018); Informe No. 2 de la Fiscalía General de la Nación, "Retención ilegal de personas por parte de las Farc- EP, citado por Revista Semana, Íd.; Jurisdicción Especial para la Paz (JEP), Sala de Reconocimiento de Verdad, de Responsabilidad, y de Determinación de los Hechos y conductas (SRVR), Auto No. 005, por el cual se avoca conocimiento del Caso No. 003 "Muertes ilegítimamente presentadas como bajas en combate por agentes del Estado", 17 de julio de 2018; Jurisdicción Especial para la Paz (JEP), Sala de Reconocimiento de Verdad, de Responsabilidad, y de Determinación de los Hechos y conductas (SRVR), Caso No. 005 Situación territorial en la región del norte del Cauca, 8 de noviembre de 2018.

[131] Angélika Rettberg, Reparación en Colombia ¿Qué quieren las víctimas?, 9 (Agencia de Cooperación Técnica Alemana, GTZ, 2008); Corte Constitucional de Colombia. Auto 004 de 2009 (M. P. Manuel José Cepeda Espinosa; 26 de enero de 2009).

[132] Ver: Departamento Nacional de Planeación, La Superación de la situación de vulnerabilidad causada por el desplazamiento forzado: Un gran reto de la política pública dirigida a las víctimas del conflicto armado (s. f.).

[133] Sentencia C-080 de 2018, parág. 4.1.11; Jurisdicción Especial para la Paz (JEP), Sección de Apelación, SA-TP-SENIT 1 de 2019, 3 de abril de 2019, parág. 114 citando a Pablo de Greiff, "Participación de las víctimas en medidas de justicia de transición”, Naciones Unidas, Documento A/HRC/34/62, 27 de diciembre de 2016. Organización de las Naciones Unidas, Asamblea General, Informe del Relator Especial sobre la promoción de la verdad, la justicia, la reparación y las garantías de no repetición, Pablo de Greiff, ONU, (Doc. A/HRC/21/46), 12 de agosto de 2012.

[134] Jurisdicción Especial para la Paz (JEP), Sección de Apelación, SA-TP-SENIT 1 de 2019, 3 de abril de 2019, parág. 114.

[135] Íd., parág. 113. 
[136] Jurisdicción Especial para la Paz (JEP), Sala de Reconocimiento de Verdad, de Responsabilidad, y de Determinación de los Hechos y conductas (SRVR), Auto 080, 28 de mayo de 2019, párr. 64.

[137] Íd., párr. 73

[138] Íd., párr. 80

[139] Íd., párr. 79 y 82

[140] JEP Colombia, Audiencia Pública para escuchar a familiares de los jóvenes de Soacha ejecutados extrajudicialmente, YouTube (17 de octubre de 2019).

* Artículo de reflexión

\section{Licencia Creative Commons CC BY 4.0}

Cómo citar este articulo: Juliette Vargas Trujillo, Participación colectiva de victimas ante la Jurisdicción Especial para la Paz (JEP), 69 Vniversitas (2020). https://doi.org/10.11144/Javeriana.vj69.pcvj 